"This is the peer reviewed version of the following article:

\title{
Acid-Catalyzed Conversion of Carbohydrates into Value-Added Small Molecules in Aqueous Media and Ionic Liquids
}

\author{
which has been published in final form at
}

https://onlinelibrary.wiley.com/doi/abs/10.1002/cssc.201702016

This article may be used for non-commercial purposes in accordance with Wiley Terms and Conditions for Self-Archiving 


\section{Acid-catalysed conversion of carbohydrates into value added} small molecules in aqueous media and ionic liquids

Iurii Bodachivskyi, ${ }^{[a]}$ Unnikrishnan Kuzhiumparambil[ ${ }^{[b]}$ and D. Bradley G. Williams*,[a]

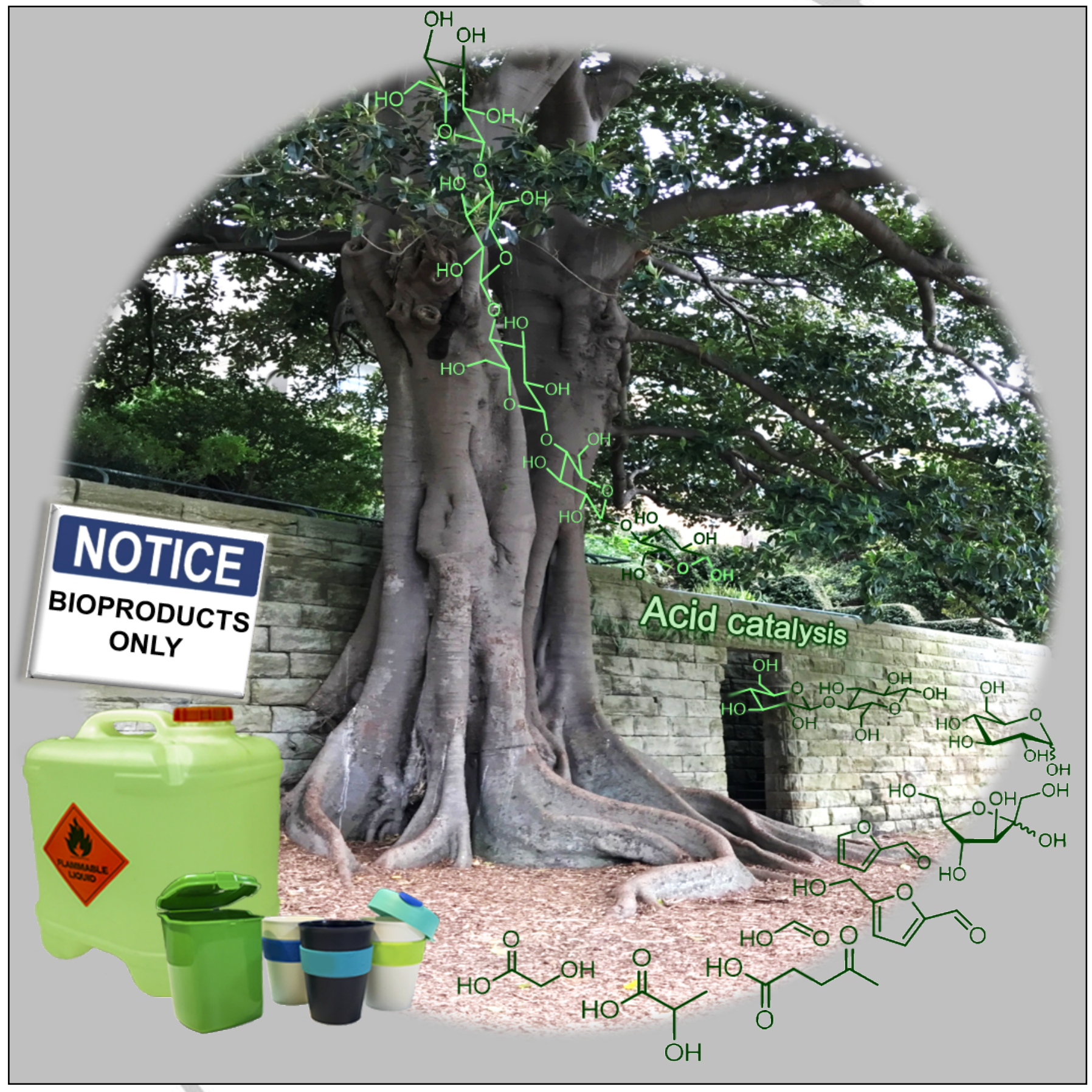


Abstract: Biomass is the only realistic major alternative source (to crude oil) of hydrocarbon substrates for the commercial synthesis of bulk and fine chemicals. Within biomass, terrestrial sources are the most accessible, and therein lignocellulosic materials are most abundant. While lignin shows promise for the delivery of certain types of organic molecules, cellulose is a biopolymer with significant potential for conversion into high volume and high value chemicals. This review covers the acidcatalysed conversion of lower value (poly)carbohydrates into valorised organic building block chemicals (platform molecules). It focuses on those conversions performed in aqueous media or ionic liquids. It does this to provide the reader with a perspective on what can be considered a best case scenario, i.e. that the overall process is as sustainable as possible.

Keywords: Carbohydrate chemistry; catalysis; green chemistry; platform chemicals

\section{Introduction}

Acids are widely used to promote manifold organic chemical transformations. The versatility of acids makes them outstanding catalysts as is reflected in their wide adoption in manufacturing and in research and development settings. ${ }^{[1]}$ They can catalyse bond forming reactions, such as addition, rearrangement, nucleophilic and electrophilic substitution, or bond cleavage reactions, such as fragmentation or elimination processes. Acid catalysts can be liquid or solid (in some rare cases gaseous) and be present as homogeneous or heterogeneous systems. Some of them catalyse reactions via proton transfer, others via accepting electron density of another atom. It has become usual to name the first group as Brønsted acid catalysts with typical representatives being hydrochloric, sulfuric, phosphoric or $p$ toluenesulfonic acids. Members of the second group are Lewis acid catalysts, among which $\mathrm{AlCl}_{3}, \mathrm{BF}_{3}, \mathrm{SnCl}_{4}$ or $\mathrm{TiCl}_{4}$ are common. ${ }^{[2]}$ Although this convention is typically applied, it is difficult to achieve pure Lewis acidity, because Brønsted acidity usually arises as a consequence of Lewis acid-Lewis base

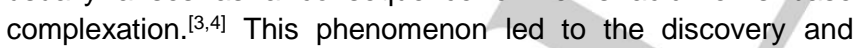
exploitation of combined acid catalysis, in which there is a high degree of research interest.

Combined acid catalysis often is defined as a conjunction of two different acids promoting a synergistic increase in the particular type of acidity (Brønsted or Lewis). The combined acids can be mixtures of two Brønsted acids (Brønsted acid-assisted Brønsted acid catalysts), Lewis acids (Lewis acid-assisted Lewis acid catalysts), or Brønsted and Lewis acids (Brønsted acid-assisted Lewis acid catalysts, or Lewis acid-assisted Brønsted acid

[a] I. Bodachivskyi, Prof. Dr. D.B.G. Williams School of Mathematical and Physical Sciences, University of Technology Sydney Broadway NSW 2007, PO Box 123 Broadway NSW 2007 (Australia); E-mail: Bradley.Williams@uts.edu.au

[b] Dr. U. Kuzhiumparambil, Climate Change Cluster (C3), University of Technology Sydney Broadway NSW 2007, PO Box 123 Broadway NSW 2007 (Australia) catalysts). ${ }^{[5]}$ Combined acid catalysis improves the outcomes of numerous processes, as has been effectively employed in asymmetric synthesis by the Yamamoto group ${ }^{[5,6]}$ and by Williams and co-workers ${ }^{[7-9]}$ in applied organic reactions, including the conversion of cellulosic materials. ${ }^{[9]}$

The growing trend towards 'Green Chemistry' and 'Sustainable Technology' has driven the research community to develop efficient new catalytic systems. These state-of-the-art catalysts are intended to meet the following requirements relating to sustainability:[10]

- be easily separable and do not produce waste products;

- be re-usable for many times without loss of activity;

- promote reactions with catalytic amounts rather than stoichiometric quantities of the catalyst;

- $\quad$ provide high selectivity under mild reaction conditions;

- be non-toxic and/or non-hazardous.

Apart from its applications in other areas, acid catalysis has made a significant impact on biomass conversion. Since the first synthesis of furfural from saccharides performed by Döbereiner ${ }^{[11]}$ in 1832 and the synthesis of levulinic acid accomplished by Malaguti ${ }^{[12]}$ in 1836, catalysis has been applied to the valorisation of biomaterials into fuels, monomers for plastics and plasticisers for them, coatings, surfactants, lubricants and lubricant additives, etc., the bulk of which are currently produced from fossil sources. ${ }^{[13-22]}$ While natural substances such as saccharides, lipids and proteins may all be convertible into useful chemicals, only lignocellulosic materials possess the scale and general ease of accessibility (i.e. physical accessibility as well as scale of renewable production) to be realistic contenders to replace substantial portions of petrochemical products. Cellulose is the most naturally abundant non-food terrestrial polymer. It consists of hundreds to thousands of $\beta(1 \rightarrow 4)$ linearly linked glucose units, and is normally entangled into plant cell walls with hemicellulose, another polysaccharide, along with the aromatic polymer lignin. Cellulose has a rigid crystalline structure in comparison with other natural polyglucosides such as starch or glycogen, as a corollary of the beta anomeric linkage. This leads to strong inter- and intrachain hydrogen bonding between hydroxyl groups, along with hydrophobic interactions. Therefore, it is virtually insoluble in water and in common organic solvents, which is a cause of substantial difficulties during chemical processing. ${ }^{[23]}$ In this field of endeavour, the philosopher's stone is the direct conversion, preferably selective, of non pretreated cellulose into value added small molecules.

Conversion of cellulose into platform molecules is a complex cascade of reactions, in which the direction and rate are determined by the nature of the catalysts present and the process conditions. The first step is solvolysis (typically hydrolysis) of cellulose into glucose or its oligomers, and is catalysed by Brønsted acids (see Scheme 1, below). ${ }^{[24]}$ Under the influence of Lewis acids, glucose can be either isomerised into fructose or undergo a retro-aldol reaction to produce other low-molecular weight substances. ${ }^{[25,26]}$ Fructose is the major product under moderate reaction conditions, while $\mathrm{C}_{2}-\mathrm{C}_{4}$ sugars appear at higher temperatures. In the presence of an appropriate catalyst under suitable reaction conditions, these compounds can be converted into carboxylic acids or their derivatives. ${ }^{[26]}$ Fructose 
can also follow a retro-aldol pathway in the presence of Lewis acids, causing bond cleavage. However, fructofuranose dehydrates in the presence of Brønsted acids, forming 5hydroxymethyl furfural (HMF), which can rehydrate into levulinic acid at elevated temperature and in the presence of water. ${ }^{[27]}$ These transformations are shown pictorially in Scheme 1 and it is immediately evident that the conversion of carbohydrates into smaller molecules proceeds as a complex set of reactions. The complexity arises principally because each stage of the conversion of cellulose is catalysed by acids, sometimes Lewis acids and sometimes Brønsted acids. The differing roles of the acid catalysts make challenging the selection of appropriate acids for transformations directly from cellulose.

At the same time, the selectivity of the set of reactions is influenced by the nature of solvent(s) present: sometimes, products interact with solvent molecules in the presence of an acid catalyst to form different compounds. For instance, aldehydes and acids are the main products in water media and water-containing systems, ${ }^{[26-28]}$ while acetals and esters predominate in alcohol solutions. ${ }^{[27,29]}$

Several reviews dedicated to the catalytic conversion of mono-, oligo- and polysaccharides into platform molecules, along with details of their applications, have been published. ${ }^{[14-18,22,28,30-35]}$ In this review we focus specifically on acid catalysed conversions in water and in ionic liquids. Both of these types of solvents have shown significant potential for the processing of cellulose into value added small molecules for different reasons. In the first, it relates in many instances to the solubility of the catalyst or hydrophilic product in the aqueous medium. In the second, the alternative solvent is in many examples functional, and also serves to separate the catalyst from the products, thereby preventing side reactions, leading to enhanced yields. It will become evident during the course of this review that these solvents hold tremendous potential to lead to commercially viable processes. Hallmarks of a 'viable process' include high yields and selectivities towards platform molecules, preferably making use of native cellulose, thereby avoiding the need for costly pretreatment, and the process should be conducted under mild reaction conditions. Ideally, it should be capable of being engineered into a continuous process rather than a batch process.

\section{Conversion of carbohydrates in water and organic solvents}

The use of water as a solvent for organic synthesis has become popular, owing to its natural abundance, extra-low toxicity, and safety during operation. ${ }^{[36]}$ Catalytic conversion of saccharides in water is no exception. Water is nonetheless a challenging solvent on industrial scale, because of treatment requirements to improve the quality of wastewater before discharge and the huge energy implications if distillation is being considered. A serious problem with the processing of saccharides in water is the selection of appropriate catalyst systems that are stable and active in aqueous media. In addition, in aqueous solutions, some reaction products can be transformed into insoluble polymers known as humins, a process that noticeably decreases yields of valuable molecules and compromises catalyst activity. These confounding issues render the selective conversion of carbohydrates into specific target compounds in high yields in water a challenging task. This section covers advances in acid-catalysed transformation of sugars in aqueous systems and systematically portrays sustainable processes that lead to various platform molecules. The section is structured to follow the cascade of events in Scheme 1. In this way, it tracks the chemistry as cellulose is converted into various products, and enables the reader to refer back to the scheme and its logic.

lurii Bodachivskyi is a $\mathrm{PhD}$ candidate in Prof. Williams's group at University of Technology Sydney working on the development of methods for a conversion of algal biomass into industrially useful small molecules. His doctorate focusses on the field of homogeneous acid catalysis and alternative solvents as a means to valorise cellulosic materials within green and sustainable processes. lurii's interests also embrace the chemistry of lipids, sulfurorganic chemistry, surface processes and molecular modelling of organic-chemical transformations.

Unnikrishnan Kuzhiumparambil obtained BSc in Chemistry followed by Masters and $\mathrm{PhD}$ in Biomolecular Sciences (2011). He carried out post doctoral research at Centre for Forensic Science, University of Technology Sydney in the area of doping control analysis and metabolism studies of designer steroids (2011-14). Currently he is a research associate at Climate Change Cluster (C3), University of Technology

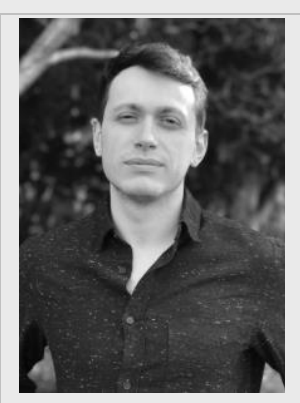

Sydney and mainly focuses on analytical method development, metabolomics and development of high value products from algal biomass.

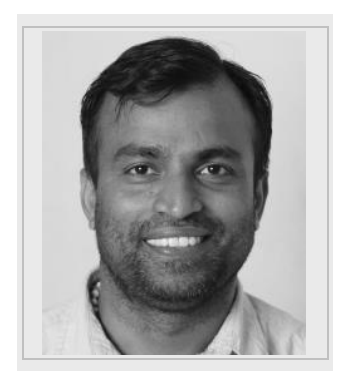

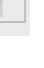

Bradley Williams has a passion for method development. His work has focussed on the use of transition metal catalysts and acidic catalysts, both Lewis and Lewis-acid assisted Brønsted acids, in high efficiency organic transformations. His interests span industrially oriented value add processes such as hydroformylation and hydroalkoxycarbonylation to advanced multistep reactions involving carbohydrate substrates. In his spare time he poses as an analytical chemist.

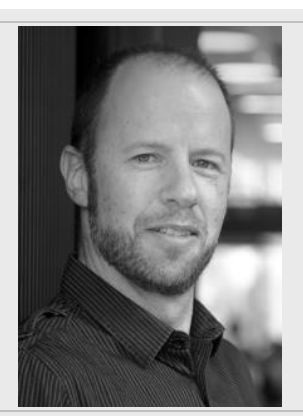




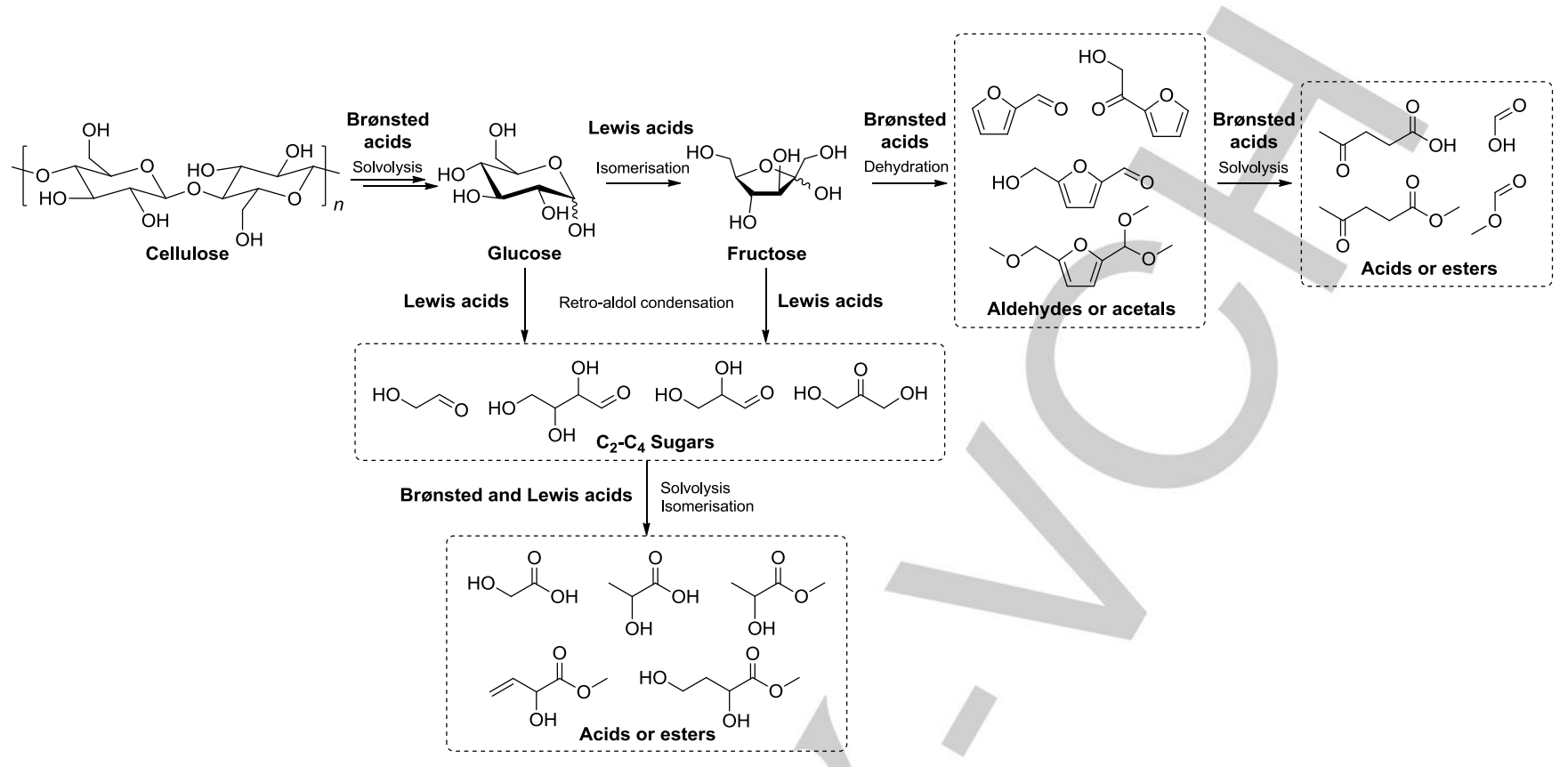

Scheme 1. Acid-catalysed cascade of cellulose conversion into small molecules.

\subsection{Oligoglucans and glucose}

The first stage of the catalytic cascade of cellulose processing in water media is the hydrolysis of the natural polymer into oligomer glucans and ultimately into monomer sugar glucose, which are of great industrial interest primarily for fermentative production of ethanol or lactic acid. ${ }^{[37,38]}$ Importantly, cellulose-derived low molecular weight sugars are not food competitive, which avoids potential ethical and social issues associated with the use of food sources of substrates for chemical products. Hydrolysis of glycosidic linkages can be productively catalysed by concentrated solutions of mineral acids or so-called cellulase-mimetic catalysts, examples being sulfonated chloride-bearing resins or sulfonated carbonised polyvinyl chloride. ${ }^{[39,40]}$ This system requires forcing reaction conditions, produces a large amount of acidic wastewater, and is corrosive towards equipment. It also requires a high loading of solid catalysts that have proved difficult to recover. An aqueous solution of $\mathrm{NaCl}$ under hydrothermal conditions $\left(220^{\circ} \mathrm{C}\right)$ overcomes some of these issues. ${ }^{[41]}$ Although this system possesses modest acidity (ca pH 5.6), it substantially lowers the molar weight of polysaccharides of microcrystalline cellulose (MCC) and lignocellulose (corncob residue, mulberry wood and corn stover) assisted by nearly complete dissolution of carbohydrates in the solvent. Potentially, such systems can be applied to large scale depolymerisation processes of cellulose and become industrially viable.

An outstanding example of an acid catalyst for the direct conversion of cellulose into glucose in aqueous media was synthesised by the solvent-free mechanochemical oxidation of activated carbon using $\mathrm{KHSO}_{4}$ or $\left(\mathrm{NH}_{4}\right)_{2} \mathrm{~S}_{2} \mathrm{O}_{8} \cdot{ }^{[2]}$ The oxidative functionalisation of activated carbon is proposed to increase the number of acidic sites (like carboxylic, ketonic, or phenolic groups), while the mechanical processing enlarges the surface area of the catalyst. Glucose yields of up to $85 \%$ are attainable during acid-catalysed hydrolysis of ball-milled cellulose, which is remarkable when compared to yields achievable using cellulase enzymes (approximately 65\%). If the energy demands of ball milling as a means of biomass pretreatment can be overcome, or if the need for it can be obviated, then this process could become commercialisable. Until then, it remains uncompetitive compared to direct fermentation of cellulose into alcohols or acids. ${ }^{[43-45]}$

\subsection{Fructose}

The next step of the cascade given in Scheme 1 is an aldoseketose isomerisation of glucose to fructose named as a Lobry de Bruyn-van Ekenstein transformation. Mechanistic studies suggest that the rate-limiting step of this reaction is a hydride shift from C2 to the $\mathrm{C} 1$ position catalysed by Lewis acids. ${ }^{[46-49]}$ The most probable pathway is thought to involve the formation of a hydroxymetal species that enables deprotonation of the $\mathrm{C} 2-\mathrm{OH}$ group (Scheme 2). Simultaneously, the Lewis-acidic metal cation $\mathrm{M}^{{ }^{n+}}$ facilitates $\mathrm{C} 2 \rightarrow \mathrm{C} 1$ hydride shift resulting in the formation of the ketose. This notion has been corroborated in the $\mathrm{AlCl}_{3}$-catalysed isomerisation of glucose. ${ }^{[50]}$ In this instance, a formation of aluminium aquo complex $\left[\mathrm{Al}(\mathrm{OH})_{2}(\mathrm{aq})\right]^{+}$as a major catalytic species was identified. Conversely, under base catalysis, the process is thought to rather proceed via hydrogen ion transfer. ${ }^{[51]}$ 


$$
\left.\left[\mathrm{M}_{2} \mathrm{O}\right)\right]^{\left(n^{+1}\right)^{+}+\mathrm{H}_{2} \mathrm{O}}
$$

Scheme 2. Proposed mechanism for Lewis acid-catalysed glucose-fructose isomerisation. ${ }^{[46-50]} \mathrm{M}=$ metal, $n=$ integer.

Unfortunately, there are not many catalysts able to promote aldose-ketose isomerisation with a high degree of efficacy in water media. A promising hydrophobic Sn-containing zeolite with beta framework topology provides the highest fructose yield (of all catalyst systems) of $31 \%$ directly from glucose. ${ }^{[52]}$ An elegant indirect approach involves a one-pot isomerisation-etherification of glucose into methyl fructoside in methanol followed by hydrolysis of the glycoside into fructose in methanol-water solution. ${ }^{[53,54]}$ Various aluminosilicates have been tested in this process and the best output of fructose was obtained with the large pore-containing $\mathrm{H}$-USY zeolite. This solid acid can be easily recovered and affords fructose in yields of $55 \%$. It is remarkable that the current industrially applied method, which is based on isomerase enzymes, provides fructose in yields of only $42 \% .{ }^{[52,55]}$

\subsection{Hydroxymethylfurfural and its derivatives}

There is current particular interest in the conversion of fructose into 5-(hydroxymethyl)furfural (HMF), which is one of the most important platform molecules within the portfolio of products that can be produced from cellulose. ${ }^{[28,33,34]}$ This compound is a raw material in the production of bio-based monomers for the polymer industry, as well as a prominent candidate for the production of biofuel. ${ }^{[22,56,57]}$ HMF synthesis requires the consecutive Brønsted acid-catalysed dehydration of fructofuranose, and is proposed to proceed as illustrated in Scheme $3^{[58-60]}$ However, alternative reaction pathways via an acyclic mechanism have been proposed. ${ }^{[61,62]}$ Because HMF is rather reactive and readily converts into humins under certain conditions, the procedure is usually conducted in the presence of organic solvents which separate the HMF from the catalyst. In many instances, watermiscible solvents such as dimethyl sulfoxide or dimethylformamide have been used, but the complexity of their recovery from aqueous systems has led to the use of non-polar and volatile solvents such as ethers, ketones, alcohols, aromatics or their mixtures. ${ }^{[63,64]}$ The immiscibility of such systems is often maintained by the addition of inorganic electrolytes $(\mathrm{NaCl}, \mathrm{KCl}$, $\mathrm{KBr}$, etc.), which additionally support the dehydration of fructose. ${ }^{[64-66]}$

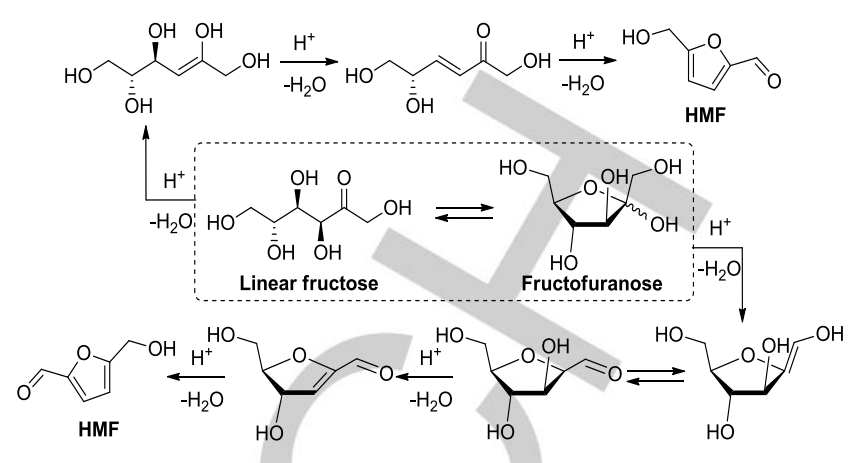

Scheme 3. Brønsted acid-catalysed fructose dehydration into HMF. ${ }^{[58-62]}$

Despite a number of examples demonstrating the successful conversion of fructose into HMF, ${ }^{[28,33,34,67-69]}$ most of them do not meet practical requirements, due to the high cost of the refined input carbohydrate substrates (mostly, fructose and sucrose). If naturally abundant glucose or polyglucosides can be converted selectively into HMF in high yields, the process could become industrially viable and so the high yielding conversion of glucose into fructose is desirable. Glucose conversion into HMF requires catalysts suitable for consecutive aldose-ketose isomerisation and fructose dehydration, and therefore must possess both Brønsted and Lewis acid sites or activity. One solution is to employ Lewis acidic metal chlorides or their combinations with hydrochloric acid. ${ }^{[25,70]}$ As shown above, metal cation hydrates can cause the release of a Brønsted base aquo complex and $\mathrm{H}_{3} \mathrm{O}^{+[a]}$ which can catalyse glucose isomerisation into fructose (Scheme 2) and dehydration of fructose into HMF. The rate of the second reaction is usually quite low and the addition of a Brønsted acid is necessary to improve the conversion and selectivity to the product. ${ }^{[25,70]}$ The combination of acids increases the rate of fructose dehydration over that obtained with $\mathrm{HCl}$ alone, but decelerates the isomerisation steps. One way to overcome this negative effect is to raise the reaction temperature which accelerates all reactions in the system. ${ }^{[25]}$ In addition, RománLeshkov and Dumesic ${ }^{[71]}$ reported that small temperature increments (for instance, from 150 to $160^{\circ} \mathrm{C}$ ) improve the rate of dehydration of fructose, thereby reducing degradation of HMF. The same observations have been noted for combinations of various metal halides and mineral acids $\left(\mathrm{HCl}, \mathrm{H}_{2} \mathrm{SO}_{4}, \mathrm{HNO}_{3}\right.$, $\left.\mathrm{H}_{3} \mathrm{PO}_{4}\right) \cdot[65]$

A peculiarity of the activity of metal chlorides in the transformation of glucose into HMF is that the conversion in biphasic systems increases with a reduction of the ionic radius of the cations in the order $\mathrm{Al}^{3+}>\mathrm{Ga}^{3+}>\mathrm{In}^{3+}$ and for the lanthanide series in the order $\mathrm{Yb}^{3+}>\mathrm{Dy}^{3+}>\mathrm{La}^{3+} \cdot{ }^{[72]}$ Apparently, this phenomenon is a result of the higher ability of small cations to coordinate hydroxyl groups in a manner that facilitates the requisite transformations, and is

[a] Although Brønsted acids are conventionally denoted as a cation $\mathrm{H}^{+}$ or $\mathrm{H}_{3} \mathrm{O}^{+}$(including instances in this review), the structure of the hydrogen ion in water varies with the concentration of the acid, and is shown to be $\mathrm{H}_{13} \mathrm{O}_{6}{ }^{+}$ in less concentrated acidic aqueous media. ${ }^{[73,74]}$ 
related to the notion of charge density (i.e. the ratio of charge to ionic radius, $z / r) \cdot{ }^{[8,75]}$ This trend has been recently confirmed and extended in a study ${ }^{[76]}$ which showed that the tetravalent Lewis acid $\mathrm{SnCl}_{4}$ in combination with $\mathrm{H}_{3} \mathrm{PO}_{4}$ affords the highest activity towards the conversion of cellobiose. However, this method fails in the attempted synthesis of HMF from cellulosic or starch-based food waste, presumably associated with the poor hydrolysis of glycosidic bonds under the reaction conditions employed. An approach which might solve this problem is to change the reaction media from water/solvent-extractant to a water/ethanol mixture. ${ }^{[77]}$ Under these conditions, HMF and HMF-ethanol acetals are produced in higher overall yield than in other solvent systems. It is possible that this is a consequence of the higher rate of alcoholysis of polysaccharides, compared with hydrolysis thereof. ${ }^{[78]}$ Table 1 summarises the outcomes of a number of combinations of substrate, catalyst and reaction medium, as discussed above.

HMF may be produced via $\mathrm{AlCl}_{3}$-catalysed transformation of biomass in a biphasic system, $\mathrm{H}_{2} \mathrm{O}-\mathrm{NaCl} /$ tetrahydrofuran under microwave heating. ${ }^{[79,80]}$ These conditions enable a range of lignocellulosic materials (corn stover, pine wood, grass, poplar) to be transformed into HMF in high yields (Table 1), and this solvent system can also be used to produce furfural in high yield $(77 \%)$. ${ }^{[81]}$ Additionally, furfural was obtained as a second major product in impressive yields up to $65 \%$ (based on the weight of pentose in the substrate), which is in the order required for a commercialisable processes. ${ }^{[82]}$ The appearance of furfural is ascribed to the presence of hemicellulose in the lignocellulosic biomass, which consists primarily of D-pentose sugars (xylose, arabinose, rhamnose, etc.) and transforms according to Scheme 4. Despite these promising results, the high cost of microwave reactors, as well as increased energy consumption as a consequence of their operation, restrict their use on an industrial scale at present.

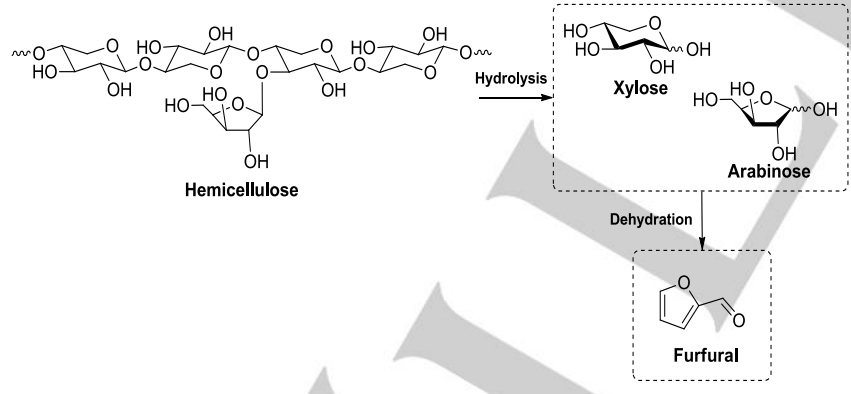

Scheme 4. Hemicellulose transformation into furfural.

Ferric phosphate has also been applied to the conversion of cellulose in biphasic system $\mathrm{H}_{2} \mathrm{O}-\mathrm{NaCl} /$ tetrahydrofuran. ${ }^{[83]}$ While almost insoluble in the reaction medium at ambient temperature, $\mathrm{FePO}_{4}$ becomes soluble and therefore a homogeneous catalyst at the reaction temperature $\left(160{ }^{\circ} \mathrm{C}\right.$, Table 1$)$. The variable catalyst solubility during the process facilitates the recovery thereof by filtration and recrystallisation of the iron salt and enables it to be reused without marked loss of activity.
Another relevant class of water-soluble Lewis acids is metal trifluoromethanesulfonates (metal triflates). Li et al. ${ }^{[84]}$ observed that metal triflates provide substantial yields of HMF during the conversion of glucose, without the addition of protic acids. This discovery relies on the ability of triflates to induce both Lewis and Brønsted acidity as was previously shown by Williams and Lawton. ${ }^{[3]}$ The conversion of glucose into HMF with metal triflates follows the same pattern as metal chlorides, in lockstep with the ionic radius of metal cation in the series $\mathrm{Al}^{3+}>\mathrm{Sc}^{3+}>\mathrm{La}^{3+}>\mathrm{Yb}^{3+}$. On the other hand, the use of higher valence state metal triflates such as $\mathrm{Hf}(\mathrm{OTf})_{4}$ and the addition of hydrochloric acid significantly improves yields of HMF (Table 1). These results show promise for the application of metal triflates to the conversion of cellulose, with the additional benefit that it is in principle possible to recycle the metal triflate catalyst. ${ }^{[84]}$ Despite the promise of this chemistry, there is an absence of information on the metal triflate-catalysed synthesis of HMF from polymers of glucose (e.g., cellulose).

Heterogeneous acid catalysts dominate over homogeneous counterparts in large scale reactions and in industry. ${ }^{[85]}$ This is also reflected in a large number of reports that are dedicated to the catalytic conversion of carbohydrates into HMF using typical acidic resins, functionalised silica, zeolites, heteropolyacids and other solids. ${ }^{[86-88]}$ Notwithstanding the ability to recover heterogeneous catalysts by filtration, homogeneous catalysts often can be efficiently recovered by the simple removal of the organic phase which contains products, ${ }^{[84,89]}$ leaving the acid catalyst in the aqueous phase. On the other hand, solid acids are frequently disposed of due to their irreversible deactivation by the formation of by-product polymer humins on their surface. ${ }^{[00]}$ Strategies to overcome this adverse effect might involve the selection of catalysts with a surface that is resistant to adsorption of macromolecular by-products or with pores large enough to remove them from the matrix of the solid. A promising group of catalysts is mesoporous solid acids. For example, mesoporous zirconium phosphate $\left(\mathrm{Zr}\left(\mathrm{HPO}_{4}\right)_{2} \cdot n \mathrm{H}_{2} \mathrm{O}\right)$ provides reasonable yields of $\mathrm{HMF}$ from glucose and can be reused in five consecutive cycles without loss of activity. ${ }^{[91]}$ Phosphated $\mathrm{TiO}_{2}$ also shows promise in appropriate biphasic systems: it enables the conversion of appropriately pre-treated microcrystalline cellulose (MCC) into HMF in surprisingly high yields (Table 1). ${ }^{\left[{ }^{[2]}\right.} \mathrm{A}$ major downside, however, is the high energy consumption during the ten-hour ball-milling of MCC and the four-hour recovery of the solid acid catalyst at $600{ }^{\circ} \mathrm{C}$. The reader will recognise that ballmilling is a technique rather frequently used as a pretreatment method for cellulose. The fact that such drastic pretreatment is required before acceptable yields of products are attainable, reflects the very high hurdle and ongoing challenge in the direct conversion of cellulose into valorised small molecules.

In an unusual setup, glucose can be converted into HMF in a mixture water/tetrahydrofuran under the pressure of carbon dioxide. ${ }^{\text {[93] }}$ Noticeably, that under applied conditions, this media forms a triphasic system $\quad \mathrm{H}_{2} \mathrm{O}-\mathrm{CO}_{2}$ (liquid)/tetrahydrofuran- $\mathrm{CO}_{2}$ (liquid) $/ \mathrm{CO}_{2}$ (gas) serving high yield and selectivity of $\mathrm{HMF}$ (Table 1). It is apparent, that $\mathrm{CO}_{2}$ possesses Lewis acidity, while in situ generated $\mathrm{H}_{2} \mathrm{CO}_{3}$ offers Brønsted acidity; therefore, the reaction media contains acid catalyst requisite to the transformation of glucose into the major product. Usefully, the process requires only mild pressure of $\mathrm{CO}_{2}$ 
Table 1. Conditions and results of acid-catalysed conversion of carbohydrates into HMF.

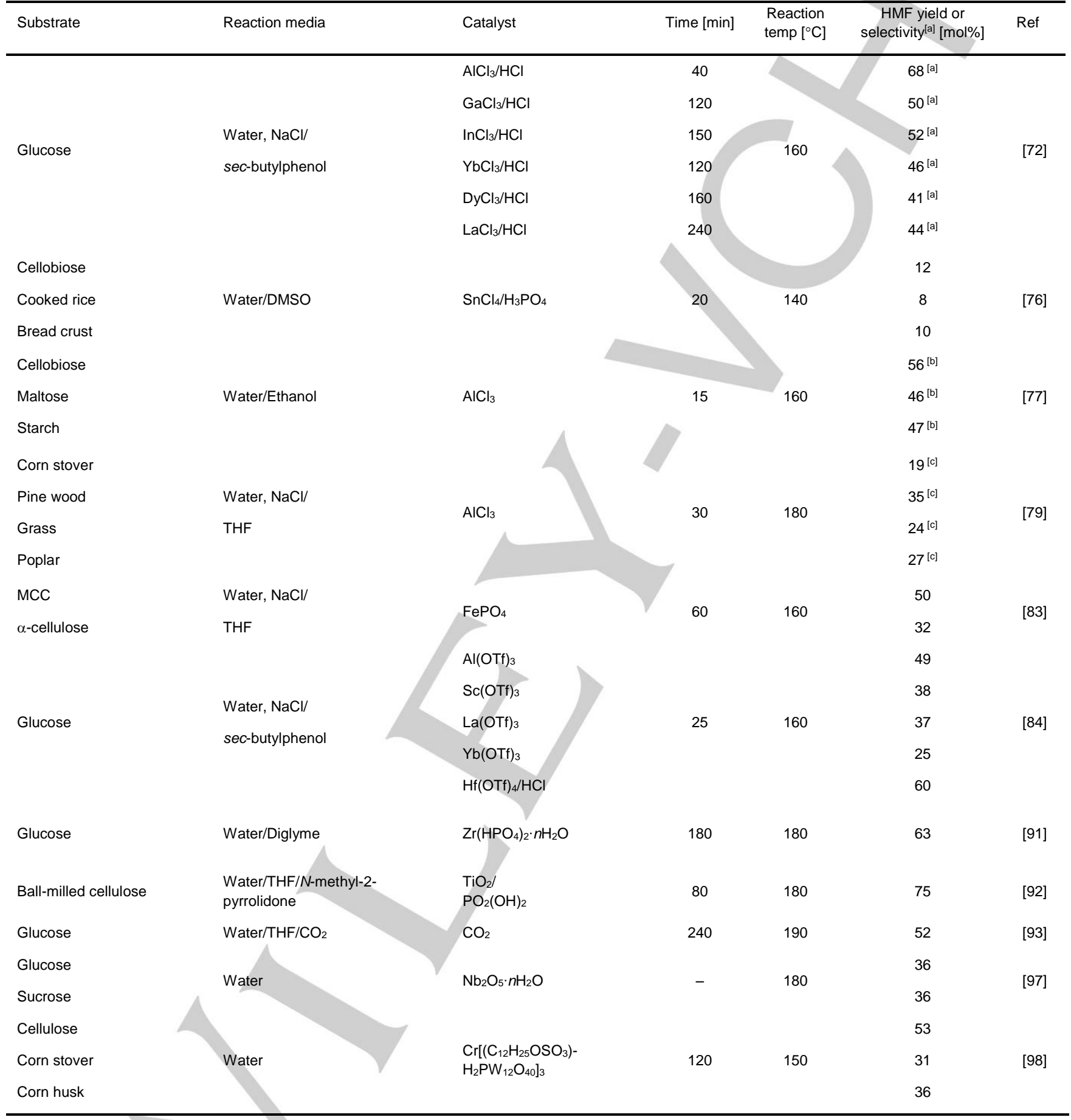

[a] HMF selectivity. [b] Total yield of HMF and HMF-ethanol acetals. [c] Yield based on the weight of hexose in biomass. MCC = microcrystalline cellulose. $n=$ integer. THF $=$ tetrahydrofuran 
(1 $\mathrm{MPa}$ ) and enable relatively easy recovery of products and solvents. ${ }^{[93]}$ Application of the process to polysaccharides will prove interesting from a scientific and practical perspective.

There remains a drive towards the efficient synthesis of HMF directly from cellulose in a single water phase to avoid the use of organic solvents in high-temperature processes. Zhang et al. ${ }^{[94]}$ have recently explored a homogeneous catalyst mixture of $\mathrm{AlCl}_{3}$ and maleic acid in the conversion of glucose into HMF in pure water. Kinetic studies reveal that this combination of acids provides high reaction rates, low activation energy for glucosefructose isomerisation and, simultaneously, shows superior selectivity towards HMF by avoiding the formation of humins. Previously, de Souza et al. ${ }^{[90]}$ tested 17 different solid acids and bases including zeolites, heteropolyacids, metal salts and oxides as catalysts for glucose conversion into HMF. Among them, only amorphous hydrated niobium oxide $\mathrm{Nb}_{2} \mathrm{O}_{5} \cdot n \mathrm{H}_{2} \mathrm{O}$, also known as niobic acid, provided $\mathrm{HMF}$ in yields above $5 \%$, and up to $28 \%$ under optimised conditions. A water-tolerant modified form of niobic acid has been used in the conversion of fructose. ${ }^{[95,96]}$ The feasibility of this kind of catalyst has been improved by the synthesis of a mesoporous niobium oxide with a large number of Lewis- and Brønsted acid sites and greater surface area. ${ }^{[97]}$ The yield of HMF was $36 \%$ from glucose and sucrose and the reactions were characterised by high rates of conversion of the carbohydrates into product (Table 1).

As far as can be determined, the catalyst providing the highest yield of HMF directly from cellulose in aqueous mixtures is a Brønsted-Lewis-surfactant combined heteropolyacid $\mathrm{Cr}\left[\left(\mathrm{C}_{12} \mathrm{H}_{25} \mathrm{OSO}_{3}\right) \mathrm{H}_{2} \mathrm{PW}_{12} \mathrm{O}_{40}\right]_{3} .{ }^{[98]}$ The micellar nature of the heteropolyacid overcomes difficulties associated with the solidsolid interaction between cellulose and the catalyst, leading to milder reaction conditions and improved yields of HMF (Table 1 ). Additionally, the hydrophobic nature of the catalyst surface prevents the adsorption of polar products and therethrough the subsequent degradation of HMF into levulinic acid or humins, and enables the catalyst to be reused at least six times. This catalyst was also used for the transformation of lignocellulosic residues (corn stover and corn husk of Xanthoceras sorbifolia). Notably, the catalyst works well even for untreated biomass giving HMF yields of 31 and $36 \%$ for corn stover and corn husk, respectively. Furfural was produced as an additional major product in yields up to $30 \%$, which is very close to the requirements for an industrially viable process. ${ }^{\left[{ }^{82]}\right.}$ While the catalyst is in principle heterogeneous, it is possible that leaching inherent to heteropolyacids leads the process to proceed via a homogeneous pathway. ${ }^{[21,98]}$

There is some progress towards the synthesis of derivatives of HMF, such as the direct conversion of cellulose into 5(chloromethyl)furfural. ${ }^{[99-101]}$ This molecule is readily accessible from lignocellulose in high yields up to $80 \%$ (based on the hexose content in biomass) and can be transformed into a large range of derivatives ${ }^{[100,101]}$ such as a high quality biofuel in the form of 5(ethoxymethyl)furfural (isolated yield 95\%). ${ }^{[102]}$ The overall process of the conversion of cellulose into 5(ethoxymethyl)furfrural is pictorially represented in Scheme 5. A down side of the synthesis of 5-(chloromethyl)furfural is the use of concentrated hydrochloric acid and an organochlorine solvent, both of which detract from the elegance of the process and which require a solution to reduce the environmental footprint thereof. Attempts to produce 5-(ethoxymethyl)furfrural in high yield directly from carbohydrates are restricted to the use of fructose, glucose, and food grade di-, or oligosaccharides (e.g., sucrose and starch), leaving room for improvement in future developments. ${ }^{\text {103-106] }}$

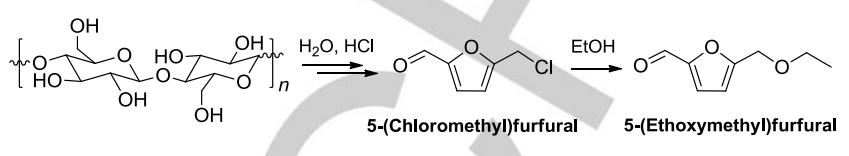

Scheme 5. Conversion of cellulose into 5-(ethoxymethyl)furfrural via 5 (chloromethyl)furfural.

\subsection{Levulinic acid, formic acid and alkyl levulinates}

Another versatile organic building block is levulinic acid, a product of the hydrolytic Brønsted acid-catalysed ring-opening reaction of HMF (Scheme 6). In contrast to the synthesis of HMF, which is sensitive to high concentrations of protic acids at elevated temperatures, the production of levulinic acid is promoted by such conditions. At the same time, levulinic acid is a relatively stable product and does not require isolation by a non-polar extractant, thereby simplifying the operating conditions. As is evident in Scheme 6, rehydration of HMF into levulinic acid also leads to the formation of formic acid, which has a wide use in applied chemistry, agricultural, fuel and pharmaceutical industry. ${ }^{[107,108]}$ There is also evidence that formic acid, a useful small molecule, can be originated directly from glucose and fructose. ${ }^{[66]}$

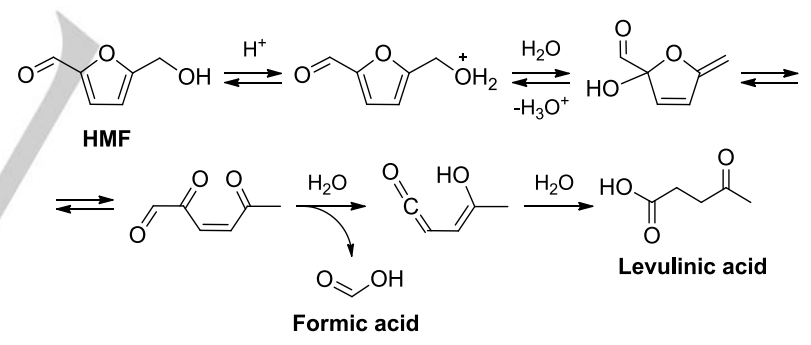

Scheme 6. Brønsted acid-catalysed HMF rehydration into levulinic acid. ${ }^{[108]}$

Levulinic acid is commercially produced by the technology developed by Biofine Renewables, LLC. ${ }^{[109]}$ The process comprises a two-step hydrolytic transformation of biomass catalysed by sulfuric acid. The first step is a rapid high-pressure hydrolysis of polysaccharides into sugar monomers and their dehydration into HMF, performed in a plug flow reactor under a pressure of 25 bar. The second step is the rehydration of HMF into levulinic acid and formic acid in a back-mix reactor under a pressure of 14 bar. Importantly, the ratios of the main products can be easily adjusted by the variation of catalyst concentration and temperature of the second stage. ${ }^{[110]}$ In this process, the yield of levulinic acid also depends on the origin of the feedstock and is produced at between 59 to $83 \%$ of the theoretical value depending on this variable. ${ }^{[108]}$ Some examples of hydrolytic 
lignocellulose conversion via Biofine technology are given in Table 2.

While the Biofine process is efficient and flexible, the sulfuric acid catalyst also promotes side reactions that produce waste products during the hydrolysis of the biomass and the separation of products. In addition, the corrosive nature of the reaction mixture together with the forcing reaction conditions leave room for improvement. Some of the efforts to solve these problems are discussed below.

Between homogeneous versus heterogeneous catalysis, the current information suggests that the former are more suitable for the synthesis of levulinic acid. For example, Weingarten, Conner and Huber ${ }^{[111]}$ described the production of levulinic acid in a yield of only $27 \%$ in the conversion of cellulose catalysed by the acidic resin Amberlyst 70. Despite these low yields and irreversible catalyst loss, a noticeable benefit of this approach is the significant reduction of by-product formation. Other resins such as Nafion SAC 13 and Dowex 50 modified with $\mathrm{Fe}^{3+}$ ions have also been applied in the conversion of cellulose into levulinic acid, but none of them can be recovered with the same catalytic activity. ${ }^{[112,113]}$ In addition, these processes require long reaction times measured in days in the case of Nafion (Table 2).

There are several successes in the homogeneous acid-catalysed transformation of polysaccharides into levulinic acid. The efficacy of metal chlorides in these reactions has been reported. ${ }^{[14]}$ Among the metal chlorides, $\mathrm{CrCl}_{3}$ shows the highest activity and affords levulinic acid in an appealing yield of $67 \%$ (Table 2). However, the authors also found that $\mathrm{CrCl}_{3}$ is consumed during the process and that chromium hydroxides precipitate during the course of the reaction, which is an issue that remains to be solved. In other work, $\mathrm{AlCl}_{3}$ was found to be useful in the conversion of hemicellulosic portion of pubescens. ${ }^{[15]}$ The combination of $\mathrm{AlCl}_{3}$ and $\mathrm{SiO}_{2}$ in water/tetrahydrofuran affords reasonable selectivity of levulinic acid of $48 \%$ (Table 2). Importantly, this process has become a precedent for the production of another platform molecule, $\gamma$-valerolactone. ${ }^{[16]} \gamma$-Valerolactone is obtained by the addition of the catalyst $\mathrm{Pt} / \mathrm{C}$ to the reaction media, which promotes both in situ generation of $\mathrm{H}_{2}$ from formic acid and reductive cyclisation of levulinic acid into its corresponding lactone. Usefully, it is possible to recover the catalyst system.

Pseudo-homogeneous catalytic systems have been developed by the research group of KU Leuven. ${ }^{[117,118]}$ These are macromolecular water soluble catalysts based on sulfonated hyperbranched poly(arylene oxindoles). Derivatives bearing chlorine or fluorine atoms as substituents provide the best catalytic activity (Table 2). It was demonstrated that the catalyst does not change in its chemical composition after the reaction, and can thus probably be reused. However, catalyst recovery involves ultrafiltration that may cause processing difficulties in industrial scale processes.

A method with substantial potential is based on the application of gaseous acid $\mathrm{SO}_{2} \cdot{ }^{[119]} \mathrm{SO}_{2}$ plays a dual role acting both as a Lewis acid and Brønsted acid catalyst. The Brønsted activity is provided through the dissolution of $\mathrm{SO}_{2}$ and formation of sulfurous acid $\mathrm{H}_{2} \mathrm{SO}_{3}$ in aqueous media. The dual acidity of the catalyst led to good yields of levulinic acid from untreated cellulose (Table 2). Usefully, the catalyst could be recovered by steam stripping. The major drawback of this process is the high reaction temperature and pressure that do not significantly differ from those of the Biofine technology and therefore offers little improvement. Nevertheless, sulfurous acid does not induce severe metal corrosion, in comparison with sulfuric acid, which may reduce capital costs.

Table 2. Conditions and results of acid-catalysed conversion of cellulosic materials into levulinic acid.

\begin{tabular}{|c|c|c|c|c|c|}
\hline Substrate & Catalyst & Time $[\mathrm{h}(\mathrm{s})]$ & Reaction temp $\left[{ }^{\circ} \mathrm{C}\right]$ & Levunic acid yield [\%] $]^{[a],[b]}$ & Ref \\
\hline Paper sludge & $\mathrm{H}_{2} \mathrm{SO}_{4}$ & $\begin{array}{l}14 \mathrm{~s} \\
0.42\end{array}$ & $\begin{array}{l}215 \\
200\end{array}$ & $71[a]$ & [109] \\
\hline Paper pulp & $\mathrm{H}_{2} \mathrm{SO}_{4}$ & $\begin{array}{l}15 s \\
0.42\end{array}$ & $\begin{array}{l}205 \\
185\end{array}$ & $\begin{array}{c}61^{[a]} \\
\text { (82 for formic acid) }\end{array}$ & [110] \\
\hline MCC & $\begin{array}{l}\text { Non-catalytic } \\
\text { Amberlyst } 70\end{array}$ & & $\begin{array}{l}220 \\
160\end{array}$ & $27^{\text {[a] }}$ & [111] \\
\hline Cellulose & Nafion SAC 13 & 120 & $190-200$ & $72^{[b]}$ & [112] \\
\hline MCC & Fe-resin & 5 & 200 & $33^{[a]}$ & [113] \\
\hline MCC & $\mathrm{CrCl}$ & 3 & 200 & $67^{[\mathrm{b}]}$ & [114] \\
\hline $\begin{array}{l}\text { Hemicellulose } \\
\text { ( } P \text {. heterocycla cv. } \\
\text { Pubescens) }\end{array}$ & $\mathrm{AlCl}_{3} / \mathrm{SiO}_{2}$ & 4 & 160 & $48^{[c]}$ & [115] \\
\hline Ball-milled MCC & $\begin{array}{l}\text { 5Cl-SHPAO } \\
5 \mathrm{~F}-\mathrm{SHPAO}\end{array}$ & 5 & 165 & $\begin{array}{l}48^{[b]} \\
47^{[b]}\end{array}$ & [118] \\
\hline Cellulose & $\mathrm{SO}_{2}$ & 0.75 & 210 & $45^{[b]}$ & [119] \\
\hline
\end{tabular}

[a] \% from theoretically possible $71.6 \%$ wt/wt. [b] mol\% based on anhydroglucose unit. [c] Levulinic acid selectivity. MCC = microcrystalline cellulose. 5CI-SHPAO or $5 \mathrm{~F}-\mathrm{SHPAO}=$ sulfonated hyperbranched poly(arylene oxindole)s with chloride or fluoride substituents in the fifth position of isatin. 
A particular trend in the conversion of carbohydrates is towards the synthesis of alkyl levulinates for use as solvents or fuel additives. ${ }^{[120]}$ For example, methyl levulinate can be selectively produced in the presence of methanol during the conversion of cellulose catalysed by combinations of various metal triflates and sulfonic acids. ${ }^{[121]}$ Although the efficacy of single entity triflate catalysts is high, it was shown that the presence of $p$ toluenesulfonic acid improves the ester yield by boosting the rate of cellulose solvolysis into sugars (Figure 1). As can be seen in Figure $1, \ln (\mathrm{OTf})_{3}$ affords the highest activity compared to the other metal triflates and gives the most active catalyst pair with 2naphthalenesulfonic acid. Turning now to industrial scale synthesis, we may note that Eni S.p.A. company has published a patent based on the conversion of lignocellulose with 2naphtalenesulfonic acid as catalyst in ethanol, 2-propanol or 1butanol. ${ }^{[122]}$ It is noteworthy that the technology can deliver ethyl, propyl and butyl levulinate in excellent yields of 95, 89 and $85 \%$ from coniferous wood. An advantage of processes performed in alcohols is the facile recovery of the catalytic system after distillation of the products. ${ }^{[121]}$

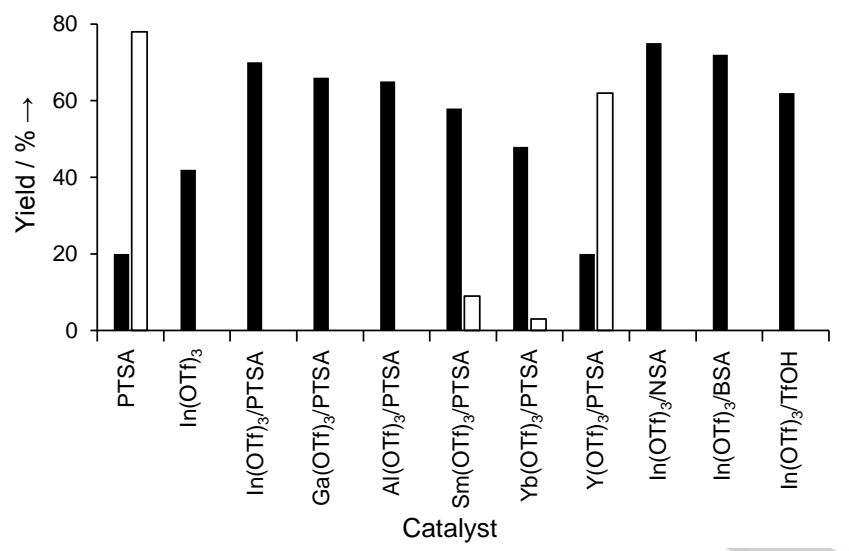

Figure 1. Acid-catalysed synthesis of methyl levulinate from cellulose. Reaction conditions: cellulose $2.5 \mathrm{mmol}$ (as a glucose unit), Lewis acid $0.02 \mathrm{mmol}$, Brønsted acid $0.1 \mathrm{mmol}$, methanol $20 \mathrm{~mL}, \mathrm{~N}_{2} 0.5 \mathrm{MPa}, 180^{\circ} \mathrm{C}, 30 \mathrm{~min}^{\left[{ }^{[121]}\right.}=$ yield of methyl levulinate. $\square=$ yield of sugars. PTSA $=p$-toluenesulfonic acid. NSA = naphthalenesulfonic acid. BSA = benzenesulfonic acid. $\mathrm{TfOH}=$ trifluoromethanesulfonic acid.

The opportunity to deliver formic acid from carbohydrates is also of particular interest; formic acid is usually produced as a byproduct of the synthesis of levulinic acid. The most striking instance of the direct conversion of carbohydrates into formic acid is the OxFA process commercialised by OxFA GmbH. This process employs the oxidative conversion of sugars with molecular oxygen using as homogeneous catalyst the Keggintype polyoxometalate $\mathrm{H}_{5} \mathrm{PV}_{2} \mathrm{Mo}_{10} \mathrm{O}_{40} \cdot 35 \mathrm{H}_{2} \mathrm{O}$ as a means of oxygen insertion into $\mathrm{C}-\mathrm{C} \sigma$-bonds, ultimately leading to formic acid and $\mathrm{CO}_{2}$ via electron-oxygen transfer mechanisms. ${ }^{[123,124]}$ The catalyst provides some activity towards the hydrolysis of glycosidic bonds and enables monosaccharides as well as oligosaccharides like xylans to be converted into formic acid in good yields (33\%) under comparably mild conditions $\left(80^{\circ} \mathrm{C}, 26 \mathrm{~h}\right.$,
30 bar $\left.\mathrm{O}_{2}\right) \cdot{ }^{[124]}$ However, cellulose is rather unreactive under such conditions and there is a need to promote the hydrolysis of the polymer using an additional source of a Brønsted acid. In one approach, ${ }^{[125]} p$-toluenesulfonic acid was employed in the process leading to the improved conversion of various cellulosic materials (beech, poplar, pine, waste paper, cyanobacteria, etc.) into formic acid in improved yields (up to 40\%) and selectivity (40-56\%) towards the target molecule.

\section{5. $\alpha$-Hydroxy acids}

In contrast to the works described above, the application of a retro-aldol pathway as a method of valorisation of cellulose is more complex and less deeply investigated. However, there are some examples of acid catalysts that enable selective processes (Table 3). The major products of the retro-aldol pathway are $\alpha$ hydroxy acids, primarily lactic and glycolic acids. These acids are also key platform chemicals used widely for the production of commercial bioplastics and for the synthesis of pyruvic and acrylic acids and other monomers. ${ }^{[126]}$

The retro-aldol reaction gives $\mathrm{C}_{2}$ and $\mathrm{C}_{4}$ sugars from glucose, and trioses (dihydroxyacetone and glyceraldehyde) from fructose, as depicted in Scheme 7. This step normally can be performed at elevated temperature using Lewis acid catalysts. ${ }^{[33]}$ Trioses are intermediates in the formation of lactic acid through the sequential stages of a retro-Michael dehydration into pyruvic aldehyde and its hydration and isomerisation into 2-hydroxy carboxylic acids. Retro-Michael dehydration is catalysed by both Lewis and Brønsted acids, while the hydration of aldehydes is typically induced by Brønsted acids, and isomerisation reactions are most frequently promoted by Lewis acids (Scheme 7). ${ }^{[26,127]}$ The synthesis of glycolic acid is also achievable from $\mathrm{C}_{2}-\mathrm{C}_{4}$ sugars; however, this reaction requires an additional retro-aldol condensation step and hydration and isomerisation reactions. ${ }^{[128]}$ Metal chlorides and other salts have been used to good effect to promote the synthesis of lactic acid from glucose. ${ }^{[129]}$ It was established that $\mathrm{AICl}_{3}$ provides the highest activity toward lactic acid which was produced in a yield of $20 \%$ at comparably low reaction temperatures. However, $\mathrm{Pb}\left(\mathrm{NO}_{3}\right)_{2}$ is more active in this reaction using ball-milled cellulose to produce a surprisingly high yield $(68 \%)$ of lactic acid ${ }^{[130]}$ and the catalyst could be recovered by capture of $\mathrm{Pb}^{2+}$ on a cation exchange resin. Nonetheless, the toxicity of lead catalysts poses problems within the concepts of green chemistry and is avoided on industrial scale.

The application of lanthanide triflates to the hydrothermal conversion of untreated cellulose into a-hydroxy acids represents something of a breakthrough. ${ }^{[131]} \mathrm{A}$ yield of $90 \%$ based on the anhydroglucose unit was achieved under optimised conditions using $\operatorname{Er}(\mathrm{OTf})_{3}$ as catalyst (Table 3). Importantly, that catalyst provided the same result even after four cycles of recovery and recycling. Its recovery required only simple distillation of water and reaction products, but on large scale this may be too energy intensive to be economically feasible. The study also found that catalyst activity depends on the metal ionic radii in a contrariwise manner compared to the above examples of HMF synthesis. The yield of lactic acid goes up with an increase of cation ionic radii and is approximately equal for $\mathrm{Er}^{3+} \approx \mathrm{Yb}^{3+} \approx \mathrm{Lu}^{3+}$. 


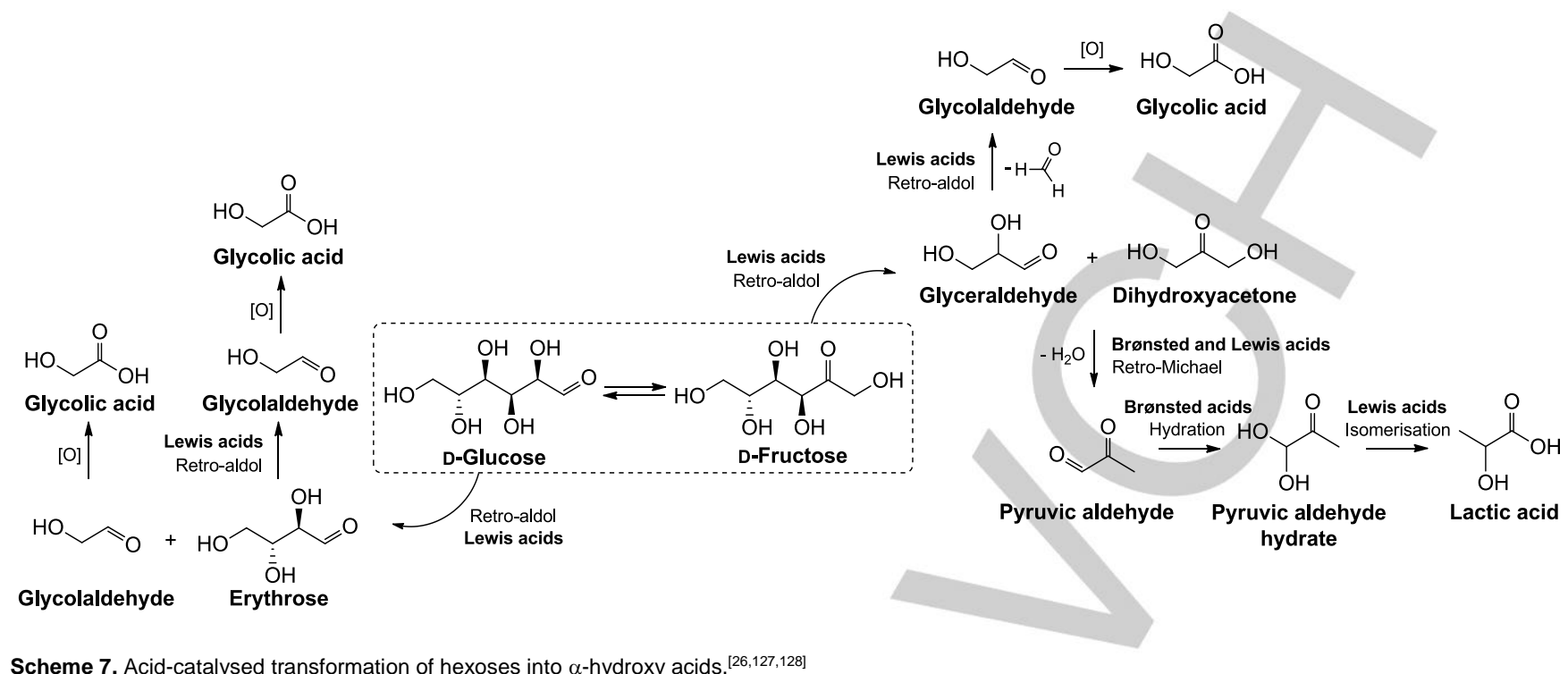

Scheme 7. Acid-catalysed transformation of hexoses into $\alpha$-hydroxy acids. ${ }^{[26,127,128]}$

Table 3. Conditions and results of acid-catalysed conversion of carbohydrates into $\alpha$-hydroxy acids.

\begin{tabular}{|c|c|c|c|c|c|}
\hline Substrate & Catalyst & Time $[\mathrm{h}]$ & Reaction temp $\left[{ }^{\circ} \mathrm{C}\right]$ & $\begin{array}{l}\text { Lactic or glycolic acid }{ }^{[\mathrm{a}]} \text { yield } \\
{[\mathrm{mol} \%]}\end{array}$ & Ref \\
\hline Glucose & $\mathrm{AlCl}_{3}$ & 6 & 140 & 20 & [129] \\
\hline \multirow[t]{6}{*}{ Ball-milled MCC } & $\mathrm{Pb}\left(\mathrm{NO}_{3}\right)_{2}$ & 4 & 190 & 68 & [130] \\
\hline & $\operatorname{Er}(\mathrm{OTf})_{3}$ & & & $90^{[b]}$ & \\
\hline & $\mathrm{Lu}(\mathrm{OTf})_{3}$ & & & 62 & \\
\hline & $\mathrm{Yb}(\mathrm{OTf})_{3}$ & & & 62 & \\
\hline & $\operatorname{Er}(\mathrm{OTf})_{3}$ & & & 62 & \\
\hline & $\mathrm{Ho}(\mathrm{OTf})_{3}$ & & & 61 & \\
\hline \multirow[t]{6}{*}{ MCC } & $\operatorname{Dy}(\mathrm{OTf})_{3}$ & 0.5 & 240 & 60 & [131] \\
\hline & $\mathrm{Sm}(\mathrm{OTf})_{3}$ & & & 58 & \\
\hline & $\mathrm{Nd}(\mathrm{OTf})_{3}$ & & & 55 & \\
\hline & $\operatorname{Pr}(\mathrm{OTf})_{3}$ & & & 53 & \\
\hline & CO & & & 48 & \\
\hline & & & & 46 & \\
\hline$\alpha$-Cellulose & & & & $49^{[a]}$ & \\
\hline Bagasse & $\mathrm{H}_{3} \mathrm{PMO}_{12} \mathrm{O}_{40}$ & 1 & 180 & $32^{[a]}$ & [128] \\
\hline Hay & & & & $28^{[a]}$ & \\
\hline
\end{tabular}

[a] Yield of glycolic acid. [b] Yield of lactic acid under the optimised catalyst loading. MCC = Microcrystalline cellulose. 
Recent investigations into the metal triflate-catalysed conversion of cellulose by the retro-aldol process are based on reactions in methanolic media. ${ }^{[29]}$ This medium leads to the production of $\alpha$ hydroxy methyl esters, including methyl lactate, methyl vinylglycolate and methyl 4-methoxy-2-hydroxybutanoate. The latter two esters are believed to form from tetrose sugars as depicted in Scheme 8 and are also considered to be platform molecules with significant potential for industrial application. ${ }^{[132,133]}$ Importantly, careful selection of the metal triflate catalyst enables the preferred reaction pathway to be followed. For example, Sn(OTf $)_{2}$ primarily catalyses the retroaldol reaction and further conversion of sugars into $\alpha$-hydroxy esters (Figure 2). Conversely, $\mathrm{Al}(\mathrm{OTf})_{3}, \mathrm{AgOTf}$ and $\mathrm{Cu}(\mathrm{OTf})_{2}$ are the best choice for selectivity towards methyl levulinate, because they accelerate dehydration-rehydration reactions. ${ }^{[29]}$ It is possible that the outcomes of the reactions depend on the interplay between Brønsted and Lewis acidic components of metal triflates. The prevailing type of catalyst acidity is usually determined by the strength of metal-ligand versus metal-solvent interactions. ${ }^{[3]}$ The first phenomenon relies on the Lewis acidity and leads to retro-aldol pathways. In contrast, binding of the solvent to the metal induces the release of a Brønsted acid which leads to rehydration products.

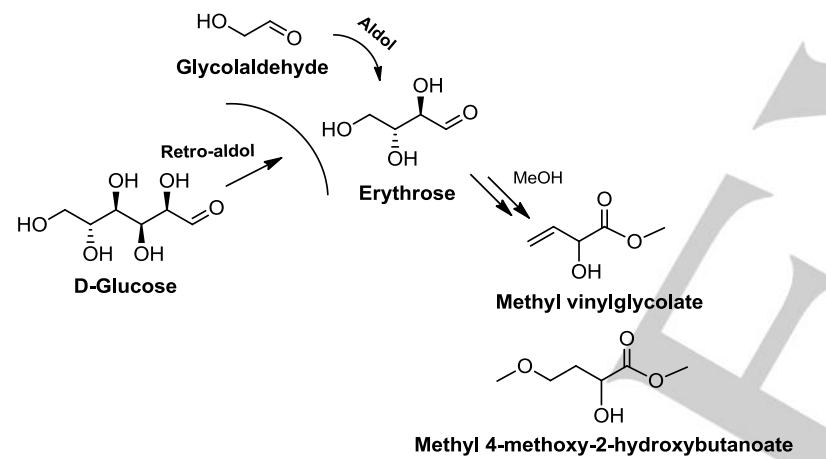

Scheme 8. Conversion of $\mathrm{C}_{2}-\mathrm{C}_{4}$ sugars into $\alpha$-hydroxy methyl esters.

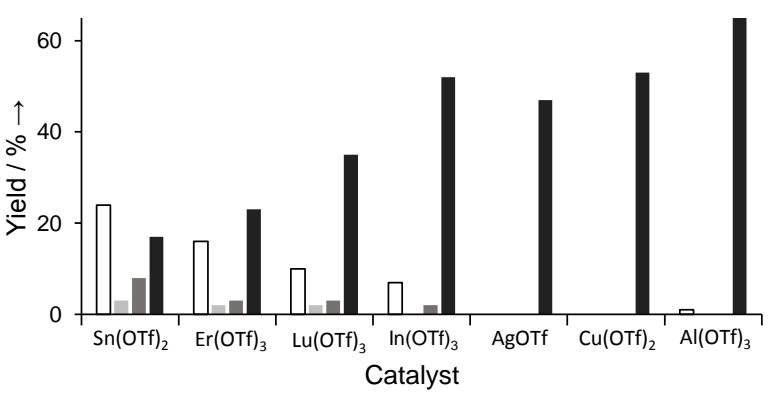

Figure 2. Metal triflate-catalysed conversion of cellulose into value added esters Reaction conditions: ball-milled cellulose $1 \mathrm{~g}$, catalyst $0.24 \mathrm{mmol}$, methanol 50 $\mathrm{mL}, 200{ }^{\circ} \mathrm{C}, 2 \mathrm{~h} \cdot{ }^{[29]} \square=$ yield of methyl lactate. ${ }^{-1}=$ yield of methyl 4-methoxy-2hydroxybutanoate. $=$ = yield of methyl vinylglycolate. $\mathbf{\square}=$ yield of methyl levulinate.
As far as can be established, there is only one instance of a successful acid-catalysed synthesis of glycolic acid from cellulose. ${ }^{[128]}$ This method is based on phosphomolybdic heteropolyacid $\mathrm{H}_{3} \mathrm{PMo}_{12} \mathrm{O}_{40}$ as catalyst under an atmosphere of oxygen. Optimisation of the reaction conditions led to the production of glycolic acid in a yield of $49 \%$ for $\alpha$-cellulose as substrate (Table 3). Quite usefully, untreated bagasse and hay produce remarkably high yields of glycolic acid, along with additional products such as formic, acetic, propionic and glyceric acids and others. Importantly, the catalyst can be recovered and be reused without loss of activity in nine consecutive runs.

There is a little progress towards to production of other valueadded molecules from carbohydrates, products such as $\mathrm{C}_{2}-\mathrm{C}_{4}$ saccharides, 2,4-dihydroxybutanoic acid, 2,5-dihydroxybut-3enoic acid, 2,4,5-trihydroxypentanoic acid, 2,4,5,6tetrahydroxyhexanoic acid, 5-(1,2-dihydroxyethyl)-3hydroxydihydrofuran-2(3H)-one and many others, which have been found in reaction media as intermediates or side reaction products. ${ }^{[134]}$ Unfortunately, there are no known chemocatalysts supporting the selective production of these molecules, which leaves significant scope for research in this field.

\section{Transformation of saccharides in ionic media}

Ionic liquids (ILs) are referred to as a class of alternative solvents which consist solely of ions and have melting points below $100^{\circ} \mathrm{C}$ Over the past few decades there has been significant focus on the chemistry of ILs ${ }^{[135]}$ and chemical processes in IL media, ${ }^{[135-}$ ${ }^{138]}$ with respect to their specific properties and the wide range of applications, including the synthesis of platform molecules. ${ }^{[138]}$ Chemical transformations of carbohydrates in alternative solvents possess manifold benefits, compared to reactions in aqueous systems. The loss of products, as well as catalyst deactivation, is markedly diminished in IL media, likely due to the inhibition of side reactions involving solvent molecules. On the other hand, some ionic systems are able to dissolve cellulose, and therefore allow processes to be performed under comparably mild conditions with a high degree of efficacy. The prime disadvantage of common ILs is their high cost, implying that only outstanding technologies are likely to be competitive in terms of the sustainable biorefinery. To demonstrate the promise and opportunity of ILs, this section focuses on the conversion of carbohydrates in various ionic solvents being quaternary ammonium salts, deep eutectic solvents (DESs) and inorganic molten salt hydrates.

\subsection{Quaternary ammonium ILs}

The cascade of cellulose conversion in ILs is somewhat similar to the steps occurring in aqueous media because water is usually added to support hydrolytic reactions. As with other reaction media, the hydrolysis of cellulose into its monomer glucose is considered to be the first stage. In this respect, there are several studies that reveal highly efficient catalytic production of glucose in 1-butyl-3-methylimidazolium chloride $\left(\left[\mathrm{C}_{4} \mathrm{mim}\right] \mathrm{Cl}\right)$. For example, a sulfonated carbon-based catalyst prepared by incomplete 
hydrothermal carbonisation and sulfonation of glucose has been applied to the degradation of MCC. ${ }^{[139]} A$ total yield of reducing sugars of $73 \%$ was achievable under optimised conditions (temperature $110^{\circ} \mathrm{C}$, reaction time $4 \mathrm{~h}$ ). This yield is significantly higher than those that have been realised with other solid acids such as HY zeolite, Amberlyst 15 or Nafion NR50 which provide yields of reducing sugars of $48 \%, 28 \%$ and $35 \%$, respectively. ${ }^{[139]}$ The latest investigations show that glucose yields can be improved using dilute sulfuric acid as catalyst. ${ }^{[140]}$ The highest yield of reducing sugars in this instance is $92 \%$ at $180{ }^{\circ} \mathrm{C}$ and 60 minutes reaction time.

The majority of papers reporting the conversion of carbohydrates in alternative solvents focus on the production of HMF. A theoretical comparative study of reaction mechanisms in water and the IL 1,3-dimethylimidazolium chloride $\left(\left[\mathrm{C}_{1} \mathrm{mim}\right] \mathrm{Cl}\right)$ found that major differences in outcomes are due to solvent effects in water and IL media. ${ }^{[141]}$ Firstly, it should be noticed that deprotonation of the $\mathrm{C} 2$ hydroxyl group may be performed by the $\mathrm{Cl}^{-}$ion of $\left[\mathrm{C}_{1}\right.$ mim $] \mathrm{Cl}$, similar to the $\mathrm{C} 2-\mathrm{C} 1$ hydride shift proposed during the glucose-fructose isomerisation catalysed by Lewis acids in water (Scheme 2). On the other hand, according to the calculated energy values isomerisation occurs via an open chain mechanism in ILs and a cyclic mechanism in aqueous systems. The authors also propose a variety of side reactions in water that are likely to be absent in ILs, and thereby account for the higher selectivity in alternative solvents.

Metal chlorides are widely used for the catalytic transformation of carbohydrates in ILs. One of the pioneer studies by Zhao et al. ${ }^{[142]}$ shows the high activity of some metal chlorides for glucose conversion in 1-ethyl-3-methylimidazolium chloride $\left(\left[\mathrm{C}_{2} \mathrm{mim}\right] \mathrm{Cl}\right)$. From a mechanistic perspective, the solvent-metal chloride interaction induces the formation of $\mathrm{MCl}^{n-}$-ions ( $\mathrm{M}=$ metal, $n=$ integer) which are proposed to catalyse the reaction. Primarily, these catalytic species boost the rate of proton transfer during the mutarotation between $\alpha$ - and $\beta$-glucose anomers, but only $\mathrm{CrCl}^{n-}$ is able to catalyse the subsequent isomerisation into fructose (Scheme 9). In addition, it was noticed that metal chlorides tend to stabilise HMF, and this effect has been shown to be highest for $\mathrm{CrCl}_{2}, \mathrm{CuCl}_{2}$, and $\mathrm{VCl}_{4} \cdot{ }^{[142]}$ Conditions and results of the most successful instances are given in Table 4.

Inspired by the above-mentioned results, many research groups have applied metal chlorides in the direct conversion of polysaccharides into HMF under various reaction conditions.

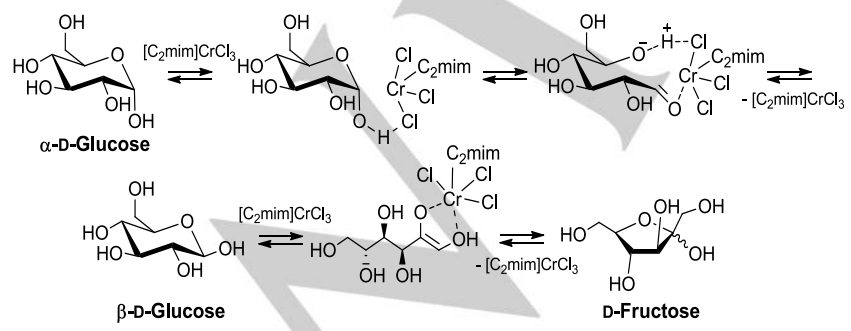

Scheme 9. Isomerisation of glucopyranose $\alpha$-anomer into fructose. ${ }^{[142]}\left[\mathrm{C}_{2} \mathrm{mim}\right]$ = 1-ethyl-3-methylimidazolium.
For example, $\mathrm{CrCl}_{3}$ was applied as a catalyst in the transformation of $\mathrm{MCC}$ in $\left[\mathrm{C}_{4} \mathrm{mim}\right] \mathrm{Cl}$ under microwave irradiation. ${ }^{[143]} \mathrm{HMF}$ yields achieved under these conditions within several minutes are comparable to or higher than those obtained from glucose or cellulose under conventional heating (Table 4). This positive outcome has been ascribed to the rate of heat transfer compared to traditional heating and a decrease of activation energy, as a result of orientation effects of polar species in the electromagnetic field of the microwave reactor. ${ }^{[144,145]}$ In addition, it has been reported that $\mathrm{CrCl}_{3}$ can catalyse the conversion of crude lignocellulose under microwave irradiation in $\left[\mathrm{C}_{4} \mathrm{mim}\right] \mathrm{Cl}^{\left[{ }^{[146]}\right.}$ The yield of HMF from corn stalk, rice straw, or pine wood was $45 \%$, $47 \%$ or $52 \%$, along with furfural in yields of $23 \%, 25 \%$, or $31 \%$, respectively. As mentioned above, the use of microwave reactors in industry is restricted due to cost implications, and so this proposed method is not industrially viable at present.

A notable advance in cellulose valorisation into HMF employs $\left[\mathrm{C}_{4}\right.$ mim] $\mathrm{Cl}$ as the solvent and $\mathrm{CrCl}_{3}$ as the catalyst. ${ }^{[147]}$ To facilitate the transformation of the polysaccharide into HMF, the cellulosic material was pretreated with dilute aqueous sodium hydroxide (3 wt\%) before the acid-catalysed reaction. This approach became useful for the conversion of a range of lignocellulosic substrates (wood chips, rice straw) affording high yields of the targeted furaldehyde (Table 4). Another benefit of the process is the mild reaction conditions, likely a consequence of the decrease of the intermolecular linkages between the fibrils of polymer after the pretreatment. However, no data were provided with regard to the recovery of ionic system.

An interesting approach has been developed by the group of Pacific Northwest National Laboratory which employed paired metal chloride Lewis acid-assisted Lewis acid catalysts in the

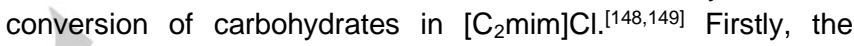
combination of $\mathrm{CrCl}_{2} / \mathrm{CuCl}_{2}$ at a high loading of the copper salt (85-95 mol\% based on the total amount of the catalyst added) boosts the rate of the hydrolysis of glycosidic bonds and therefore of the yield of glucose. However, optimum selectivity for HMF requires an excess of chromium salt ( $83 \mathrm{~mol} \%$ of the catalyst). Regulation of the reaction parameters and elaboration of the recovery procedure through a multistep extraction using methyl isobutyl ketone enable the process to reach a steady yield of HMF of $57 \%$. The same group also studied combinations of $\mathrm{PdCl}_{2} / \mathrm{CuCl}_{2}$ in cellulose transformations. ${ }^{[149]}$ In spite of the low yield of HMF $(17 \%)$, these paired metal chlorides are shown to efficiently disrupt the long-range interactions between the solvent ions and thereby improve cellulose solubility and its hydrolysis. An important finding in paired Lewis acid-catalysed reactions was the discovery that various combinations of metal chlorides catalyse the conversion of cellulose in $\left[\mathrm{C}_{2} \mathrm{mim}\right] \mathrm{Cl}$ not only to $\mathrm{HMF}$ but also to other furan derivatives such as furfural and furyl hydroxymethyl ketone, which are all important high value commodity products. ${ }^{[150]}$ The general hypothesis is that intermediate 1,2-diketones transform into furfural or furyl hydroxymethyl ketone, according to Scheme 10. It is interesting to point out that the combination $\mathrm{CrCl}_{3} / \mathrm{CuCl}_{2}$ provides the highest yield of $\mathrm{HMF}$ in reaction times as brief as 10 minutes. In turn, $\mathrm{FeCl}_{3} / \mathrm{CuCl}_{2}$ improves the selectivity to and yield of furfural and furyl 
Table 4. Conditions and results of acid-catalysed conversion of carbohydrates into HMF in various ILs.

\begin{tabular}{|c|c|c|c|c|c|c|}
\hline Substrate & Reaction media & Catalyst & Time [min] & Reaction temp $\left[{ }^{\circ} \mathrm{C}\right]$ & HMF yield [mol\%] & Ref \\
\hline \multirow{4}{*}{ Glucose } & \multirow{4}{*}[\mathrm{C}_{2}\mathrm{mim}]{$\mathrm{Cl}$} & $\mathrm{CrCl}_{2}$ & \multirow{4}{*}{180} & \multirow{4}{*}{100} & 70 & \multirow{4}{*}{ [142] } \\
\hline & & $\mathrm{CrCl}_{3}$ & & & & \\
\hline & & $\mathrm{PtCl}_{4}$ & & & & \\
\hline & & $\mathrm{AlCl}_{3}$ & & & 10 & \\
\hline MCC & {$\left[\mathrm{C}_{4} \mathrm{mim}\right] \mathrm{Cl}$} & $\mathrm{CrCl}_{3}$ & 2 & $400 W^{[a]}$ & 61 & [143] \\
\hline Wood chops & \multirow{2}{*}[\mathrm{C}_{4}\mathrm{mim}]{$\mathrm{Cl}$} & \multirow{2}{*}{$\mathrm{CrCl}_{3}$} & \multirow{2}{*}{120} & & 79 & \multirow{2}{*}{ [147] } \\
\hline Rice straw & & & & & 76 & \\
\hline MCC & {$\left[\mathrm{C}_{2} \mathrm{mim}\right] \mathrm{Cl}$} & $\mathrm{CuCl}_{2} / \mathrm{CrCl}_{2}$ & 480 & 120 & 57 & [148] \\
\hline MCC & {$\left[\mathrm{C}_{2} \mathrm{mim}\right] \mathrm{Cl}$} & $\mathrm{CuCl}_{2} / \mathrm{CrCl}_{3}$ & 10 & 140 & 39 & [150] \\
\hline MCC & {$\left[\mathrm{C}_{4} \mathrm{mim}\right] \mathrm{Cl}$} & SCC & 15 & 160 & 41 & [151] \\
\hline MCC & $\begin{array}{l}{\left[\mathrm{C}_{2} \mathrm{mim}\right] \mathrm{OAc} /} \\
{\left[\mathrm{C}_{4} \mathrm{SO}_{3} \mathrm{Hmim}\right] \mathrm{CH}_{3} \mathrm{SO}_{3}}\end{array}$ & $\mathrm{CuCl}_{2}$ & 210 & 160 & 70 & [153] \\
\hline MCC & $\begin{array}{l}{\left[\mathrm{C}_{3} \mathrm{SO}_{3} \mathrm{Hmim}\right] \mathrm{HSO}_{4} /} \\
\mathrm{DMSO} /\end{array}$ & $\mathrm{InCl}_{3}$ & 300 & 160 & 45 & [154] \\
\hline Ball-milled MCC & $\begin{array}{l}{\left[\mathrm{C}_{2} \mathrm{OHmim}\right] \mathrm{Cl} /} \\
{\left[\mathrm{C}_{4} \mathrm{SO}_{3} \mathrm{Hmim}\right] \mathrm{CF}_{3} \mathrm{SO}_{3}}\end{array}$ & $\mathrm{CrCl}_{2}$ & 240 & 140 & 62 & [155] \\
\hline Cotton linters & \multirow{2}{*}[\mathrm{C}_{4}\mathrm{mim}]{$\mathrm{Cl} / \mathrm{DMA} / \mathrm{LiCl}$} & $\mathrm{CrCl}_{2} / \mathrm{HCl}$ & \multirow{2}{*}{120} & \multirow{2}{*}{140} & 54 & \multirow{2}{*}{ [157] } \\
\hline Corn stover & & $\mathrm{CrCl}_{3} / \mathrm{HCl}$ & & & 48 & \\
\hline \multirow{2}{*}{ MCC } & {$\left[\mathrm{C}_{4} \mathrm{mim}\right] \mathrm{Cl} /$} & \multirow{2}{*}{$\mathrm{AlCl}_{3}$} & \multirow{2}{*}{540} & \multirow{2}{*}{150} & \multirow[b]{2}{*}{55} & \multirow{2}{*}{ [159] } \\
\hline & & & & & & \\
\hline MCC & TBAC & $\mathrm{CrCl}_{3} / \mathrm{HCl}$ & 90 & 140 & 44 & [160] \\
\hline Inulin & $\begin{array}{l}\mathrm{ChCl} / \mathrm{C}_{2} \mathrm{H}_{2} \mathrm{O}_{4} \cdot 2 \mathrm{H}_{2} \mathrm{O} / \\
\mathrm{AcOEt}\end{array}$ & - & & 80 & 64 & [163] \\
\hline Pretreated MCC ${ }^{[b]}$ & $\mathrm{ZnCl}_{2} \cdot 4.44 \mathrm{H}_{2} \mathrm{O}$ & $\mathrm{HCl}$ & & 120 & 30 & [174] \\
\hline MCC & $\mathrm{ZnCl}_{2} \cdot 3 \mathrm{H}_{2} \mathrm{O} / \mathrm{MIBK}$ & $\mathrm{HCl}$ & 40 & 150 & 81 & [175] \\
\hline
\end{tabular}

[a] Heating under microwave irradiation. [b] Cellulose was heated in $\mathrm{ZnCl}_{2} \cdot 4 \cdot 44 \mathrm{H}_{2} \mathrm{O}$ at $70{ }^{\circ} \mathrm{C}$ for $12 \mathrm{~h}$. $\left[\mathrm{C}_{2}\right.$ mim] $\mathrm{Cl}=1$-ethyl-3-methylimidazolium chloride. [ $\mathrm{C}_{2}$ mim] $\mathrm{OAc}$ $=1$-ethyl-3-methylimidazolium acetate. $\left[\mathrm{C}_{2} \mathrm{OHmim}\right] \mathrm{Cl}=1$-(2-hydroxyethyl $)-3$-methylimidazolium chloride. $\left[\mathrm{C}_{3} \mathrm{SO}_{3} \mathrm{Hmim}\right] \mathrm{HSO} \mathrm{H}_{4}=1$-methyl-3-(3-sulfopropyl)-

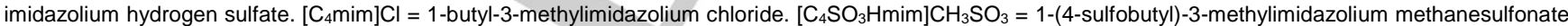
$\left[\mathrm{C}_{4} \mathrm{SO}_{3} \mathrm{Hmim}\right] \mathrm{CF}_{3} \mathrm{SO}_{3}=1$-(4-sulfobutyl)-3-methylimidazolium trifluoromethanesulfonate. $\mathrm{AcOEt}=$ ethyl acetate. $\mathrm{ChCl}=\mathrm{choline}$ chloride. $\mathrm{DMA}=$ dimethylacetamide $\mathrm{DMSO}=$ dimethylsulfoxide. $\mathrm{MCC}=$ microcrystalline cellulose. $\mathrm{MIBK}=$ methyl isobutyl ketone. $\mathrm{SCC}=$ sulfonated carbonised cellulose. TBAC = tetrabutylammonium chloride.

hydroxymethyl ketone (16 and $11 \%$, respectively) under the same process conditions. In both cases, longer reaction times result in losses of products as a consequence of side processes.

Heterogeneous acid catalysis also has been applied to the transformation of carbohydrates into HMF in alternative solvents. The conversion of glucose in $\left[\mathrm{C}_{4} \mathrm{mim}\right] \mathrm{Cl}$ in reactions catalysed by various solid acids (clays, zeolites, resins, heteropolyacids, sulfated oxides and carbonised carbohydrates) has been investigated. ${ }^{[151]}$ As can be seen in Figure 3, the highest conversion of glucose and yield of HMF are delivered by sulfonated carbonised saccharides, primarily derived from cellulose. This material has been identified as a recoverable efficient catalyst that is suitable for cellulose conversion as well (Table 4). Notwithstanding problems associated with the high loading of the sulfonated carbocatalysts (optimally found to be 40 wt $\%$ based on starting materials), they show promise with regard to low cost and high selectivity. However, it is important to note the major role performed by $\left[\mathrm{C}_{4} \mathrm{mim}\right] \mathrm{Cl}$ in the catalytic reactions, 


$$
\text { Furfural }
$$

Scheme 10. Formation of furfural and furyl hydroxymethyl ketone from a 1,2diketone intermediate. ${ }^{[150]}$

as explained above (i.e. to promote proton transfer reactions). Neither water nor common organic solvents are able to afford high yields of HMF within the process (Figure 4). It is likely that the benefits of the IL system are derived from several phenomena, namely simultaneous enhancement of the solubility of carbohydrates in the IL and improved stability of the products in the IL, as well as the improvement of glucose-fructose isomerisation.

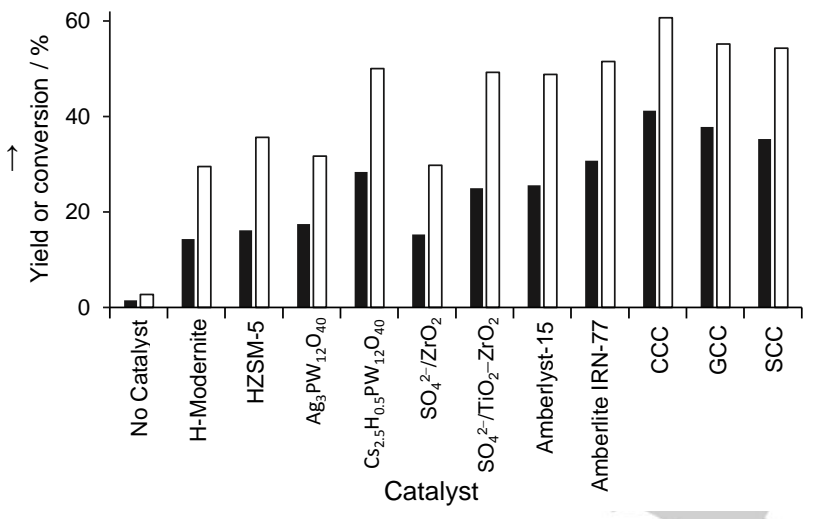

Figure 3. Transformation of glucose into HMF catalysed by various solid acids. Reaction conditions: glucose $100 \mathrm{mg}$, catalyst $40 \mathrm{mg},\left[\mathrm{C}_{4} \mathrm{mim}\right] \mathrm{Cl} 1 \mathrm{~g}, 140{ }^{\circ} \mathrm{C}$ $30 \mathrm{~min}^{\left[{ }^{151]}\right.} \mathbf{\square}=$ yield of HMF. $\square=$ conversion of glucose. CCC, GSS, SCC = cellulose, glucose and starch-derived carbonaceous catalysts respectively.

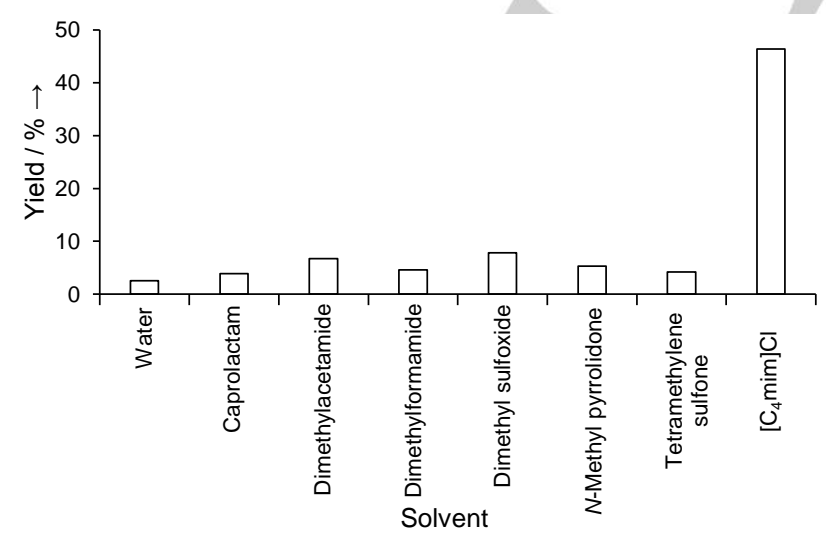

Figure 4. Glucose conversion into HMF in various solvents. Reaction conditions: glucose $100 \mathrm{mg}$, sulfonated carbonised cellulose $40 \mathrm{mg}$, solvent 1 $\mathrm{g}, 160^{\circ} \mathrm{C}, 15 \mathrm{~min} \cdot{ }^{[151]}\left[\mathrm{C}_{4} \mathrm{mim}\right] \mathrm{Cl}=1$-butyl-3-methylimidazolium chloride.
The potential of acidic ILs to perform the dual roles of reaction medium and co-catalyst has been explored. ${ }^{[152]}$ For example, various acidic ILs combined with 1-ethyl-3-methylimidazolium acetate $\left(\left[\mathrm{C}_{2} \mathrm{mim}\right] \mathrm{OAc}\right)$ have been investigated for the transformation of cellulose into HMF. ${ }^{[153]}$ Mixtures of 1-(4-sulfobutyl)3-methylimidazolium methanesulfonate $\left(\left[\mathrm{C}_{4} \mathrm{SO}_{3} \mathrm{Hmim}\right] \mathrm{CH}_{3} \mathrm{SO}_{3}\right)$ and $\mathrm{CuCl}_{2}$ provide the highest yield of HMF. Subsequent work using 1-methyl-3-(3-sulfopropyl)-imidazolium hydrogen sulfate $\left(\left[\mathrm{C}_{3} \mathrm{SO}_{3} \mathrm{Hmim}\right] \mathrm{HSO}_{4}\right)$ combined with $\mathrm{InCl}_{3}$ suffered lower yields of the major products and a requirement for longer operation times (Table 4). ${ }^{[154]}$ The combination of $\mathrm{CrCl}_{2}$ and 1-(4-sulfobutyl)-3methylimidazolium trifluoromethanesulfonate $\left(\left[\mathrm{C}_{4} \mathrm{SO}_{3} \mathrm{Hmim}\right]\right.$ $\mathrm{CF}_{3} \mathrm{SO}_{3}$ ), used in the biphasic system 1-(2-hydroxyethyl)-3methylimidazolium chloride $\left(\left[\mathrm{C}_{2} \mathrm{OHmim}\right] \mathrm{Cl}\right)$ and 1,2dimethoxyethane, gives significant yields of HMF (Table 4). ${ }^{[155]}$ It is possible to shift the process towards the formation of levulinic acid using the $\mathrm{IL}\left[\mathrm{C}_{3} \mathrm{SO}_{3} \mathrm{Hmim}\right] \mathrm{HSO}_{4}$ and an excess of water. ${ }^{[156]}$ This shift is likely to be induced by the rehydration of HMF at higher loadings of water, as well as by hydrolysis of the IL into sulfuric acid which promotes this reaction. One major disadvantage of this approach is an application of microwave heating before a reasonable yield can be realised.

Imidazolium-based ILs improve the efficacy of the process in terms of higher HMF output and some flexibility of the product portfolio, in comparison with conventional solvents. On the other hand, ILs are costly, which represents something of a stumbling block for the industrial application of the chemistry. One potential resolution has been the addition of the well-known cellulose solvent mixture of $\mathrm{N}, \mathrm{N}$-dimethylacetamide/ $\mathrm{LiCl}$ to $\left[\mathrm{C}_{2} \mathrm{mim}\right] \mathrm{Cl}$, to decrease the amount of IL consumed during cellulose conversion processes. ${ }^{[157,158]}$ This ionic system in the presence of a catalytic mixture of $\mathrm{CrCl}_{2}$ or $\mathrm{CrCl}_{3}$ and hydrochloric acid is suitable for the direct conversion of cellulose, as well as lignocellulosic biomass, providing HMF in yields of up to $54 \%$ and $48 \%$, respectively (Table 4). In addition, furfural was recovered in a yield of $34 \%$ from corn stover. However, the toxicity of dimethylacetamide, the high catalyst loading (up to $35 \mathrm{~mol} \%$ based on the anhydroglucose unit) and problems of solvent reuse complicate the implementation of this method. This issue can be partially resolved by the combination of dimethylsulfoxide and $\left[\mathrm{C}_{4}\right.$ mim $] \mathrm{Cl} .{ }^{[159]}$ It was found that $\mathrm{AlCl}_{3}$ affords a reasonable yield of HMF in this mixture under optimised reaction conditions and that the system can be reused in 5 reaction cycles with only slight loss of activity (Table 4). Tetrabutylammonium chloride, which is considered to be a relatively inexpensive alternative to imidazolium-based ILs, ${ }^{[160]}$ also shows some promise. A yield of $44 \%$ of $\mathrm{HMF}$ was obtained in tetrabutylammonium chloride during the conversion of cellulose catalysed by a combination of $\mathrm{CrCl}_{3}$ and hydrochloric acid. The possibility of solvent and catalyst recovery has been surveyed and stable synthesis results have been determined for 5 reaction cycles.

\subsection{DESs}

While common ILs suffer a number of drawbacks as mentioned, DESs show significant promise. DESs are a class of ionic systems 
formed from a eutectic mixture of Brønsted or Lewis acids and bases and have general formula

$\mathrm{Cat}^{+} \mathrm{X}^{-} \mathrm{zY}$

where $\mathrm{Cat}^{+}$is commonly ammonium, phosphonium, or sulfonium cation, $X$ is a halide ion, and $z$ is the number of acid molecules $Y{ }^{[161]} A$ major advantage of DESs is the ease of their preparation that usually involves a single-step combination of ammonium salts with a metal salt or hydrogen bond donor under solvent-free conditions. Additionally, DESs may be prepared from environmentally benign and inexpensive materials and many of these solvents are considered to be relatively non-toxic and biodegradable substances. ${ }^{[162]}$

DESs that consist of choline chloride $(\mathrm{ChCl})$ and organic acids possess the intrinsic Brønsted acidity needed for certain catalysed reactions. For instance, the solvent produced by blending $\mathrm{ChCl}$ and oxalic or citric acid has been applied for the ready synthesis of HMF from inulin. ${ }^{[163]}$ Inulin is a non-digestible fructose oligomer with occasional chain terminating glucosyl moieties, which transforms into HMF according to Scheme 11. The high yield of the value added molecule can be attained the surprisingly low temperature of $80{ }^{\circ} \mathrm{C}$ (Table 4). This result is perhaps the lowest known temperature for the efficient conversion of oligosaccharides into HMF. DESs based on $\mathrm{ChCl}$ and citric acid have been used for the conversion of hemicellulose into furfural, in the presence of the Lewis acid catalyst $\mathrm{AlCl}_{3}{ }^{[164]}$ The proposed mechanism suggests that the combined acids are able to promote both xylose-xylulose isomerisation, as well as xylulose dehydration into furfural. As a result, the furfural yield can reach $73 \%$. It is noteworthy that in both cases the acidic DES could be recovered and reused in the process.

Another type of DES derived from natural molecules is a eutectic mixture of $\mathrm{ChCl}$ and certain carbohydrates. Ilgen et al. ${ }^{[165]}$ have reported acid-catalysed conversion of various saccharides into HMF in their highly concentrated low melting mixtures (the ratio of carbohydrate to $\mathrm{ChCl}$ was between 1:1-1.5). All of the mono-, diand oligosaccharides that were explored give stable melts in combination with $\mathrm{ChCl}$ at temperatures below $100{ }^{\circ} \mathrm{C}$, but their conversion into product strongly depends on the nature of the starting materials and the catalyst (Figure 5). A possible explanation for this observation is the likelihood that each saccharide is converted by a different mechanism from the others. As far as can be determined, there is no information relating to the chemical conversion of cellulose in DESs, despite several papers dedicated to cellulose pretreatment in $\mathrm{ChCl}$-based melts. ${ }^{[166-169]}$

\subsection{Inorganic molten salt hydrates}

Recent research applying alternative solvents for cellulose conversion has been particularly focused on the use of inorganic molten salt hydrates. These are inorganic salts contain water tightly bound to the inner coordination sphere of the cation in quantities approaching the highest coordination number of the central ion. ${ }^{[170]}$ Bearing in mind that such inorganic salts possess intrinsic Lewis acidity, along with extremely low vapour pressures,

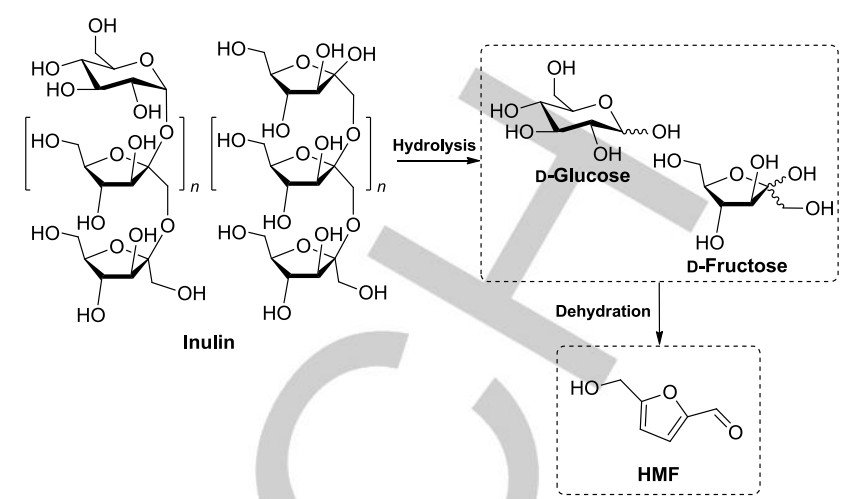

Scheme 11. Conversion of inulin into HMF. $n=$ integer.

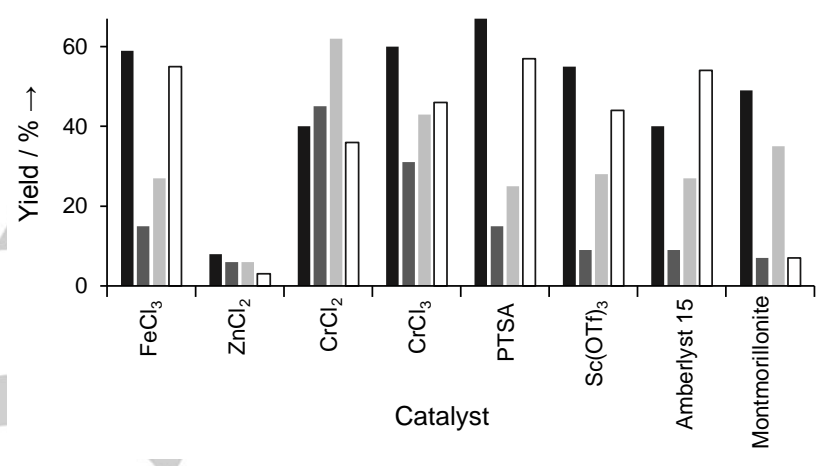

Figure 5. Acid-catalysed transformations of various sugars into HMF in their highly concentrated melting mixtures. Reaction conditions: catalyst $10 \mathrm{~mol} \%$ (Amberlyst 15 and Montmorillonite $10.0-12.5 \mathrm{wt} \%$ based on sugar), $100{ }^{\circ} \mathrm{C}, 30$ $\mathrm{min} .{ }^{[165]}=$ fructose $/ \mathrm{ChCl}(1: 1.5) . \quad=$ glucose $/ \mathrm{ChCl}(1: 1.5)$. $\square=$ sucrose $/ \mathrm{ChCl}(1: 1) . \square=$ inulin/ $\mathrm{ChCl}(1: 1) \cdot \mathrm{PTSA}=p$-toluenesulfonic acid

they demonstrate characteristics consistent with 'green' precepts and are therefore budding candidates for cellulose processing.

A number of molten salt hydrates have been demonstrated to be suitable for the dissolution, swelling and decomposition of cellulose. ${ }^{[171,172]}$ However, only $\mathrm{ZnCl}_{2} \cdot n \mathrm{H}_{2} \mathrm{O}(n=3-4)$ has presently found an application in the chemical conversion of this polysaccharide into platform molecules. ${ }^{[173-175]} \mathrm{ZnCl}_{2} \cdot n \mathrm{H}_{2} \mathrm{O}$ is considered to be an IL, possessing the formula $\left[\mathrm{Zn}\left(\mathrm{OH}_{2}\right)_{6}\right]\left[\mathrm{ZnCl}_{4}\right]$ in the case of $n=3 .^{[176,177]}$ The high dissolving power of such ILs might be attributed to the coordination and the strong interaction between the hydroxyl groups of the solvent and the polymer. ${ }^{[177]}$ These solvent-substrate interactions may lead to the specific pathways in the transformation of cellulose that will be described below.

Furyl hydroxymethyl ketone may be prepared from cellulose in $\mathrm{ZnCl}_{2} \cdot 3.36 \mathrm{H}_{2} \mathrm{O}$ under microwave irradiation, and without the addition of a solvent-extractant. ${ }^{[173]}$ In contrast to the method detailed above for the formation of this ketone (Scheme 10), the authors postulated another mechanism that proceeds through the intermediate sugar with a carbonyl group on the third carbon atom 
(Scheme 12). The highest yield of furyl hydroxymethyl ketone was only $12 \%$, which is probably attributable to the decomposition of the product/s in the acidic reaction media.
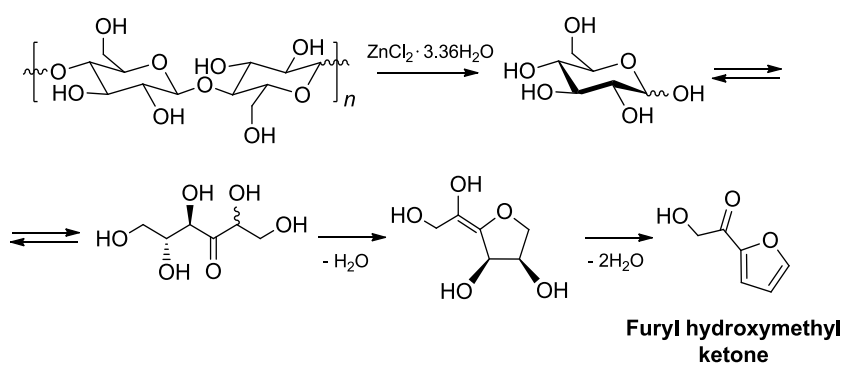

Scheme 12. Cellulose conversion into furyl hydroxymethyl ketone in $\mathrm{ZnCl}_{2} \cdot 3.36 \mathrm{H}_{2} \mathrm{O} \cdot{ }^{[173]}$

A study dedicated to the conversion of cellulose in $\mathrm{ZnCl}_{2} \cdot n \mathrm{H}_{2} \mathrm{O}$, where the number $n$ was carefully controlled, showed that selectivity can be shifted to the formation of HMF via the addition of Brønsted acid catalysts and the use of conventional heating. ${ }^{[174,175]}$ For example, in $\mathrm{ZnCl}_{2} \cdot 4 \cdot 44 \mathrm{H}_{2} \mathrm{O} / \mathrm{HCl}$, $\mathrm{HMF}$ is obtained in a yield of $30 \%$ from treated cellulose (Table 4). ${ }^{[174]}$ This result can be markedly improved upon by the addition of methyl isobutyl ketone to the reaction system as a solventextractant, and sodium chloride for enhancing the removal of HMF from the polar phase. ${ }^{175]}$ Usefully, a high yield of HMF of about $80 \%$ was reproducibly obtained in 4 catalytic runs. This is arguably the benchmark result in HMF synthesis directly from cellulose. The major weakness of the processes is the high loading of catalyst hydrochloric acid (up to 3 equivalents based on anhydroglucose), which provides a barrier to its acceptance in larger scale processes. It therefore remains an unsolved problem to successfully convert cellulose in such systems into one or two major products in high yields under relatively mild reaction conditions.

\section{Conclusions and outlook}

There is current and growing interest in the chemocatalytic conversion of carbohydrates into industrially important products. The dramatic growth in publication and patent numbers during the past two decades clearly exemplifies the movement towards the acid-catalysed synthesis of bio-derived building-block chemicals with promise to be replacements for common non-renewable crude oil-based products. Notwithstanding the many successful laboratory approaches, a number of problems persist for practical applications. For instance, in most examples the production of HMF remains based on refined digestible sugars, like fructose or sucrose, which on large scale becomes food competitive, potentially becoming a source of moral, ethical and social problems. Nevertheless, laboratory scale investigations add substantial knowledge and understanding relating to these transformations, upon which next generation technologies will no doubt be based. Meanwhile, the technology itself demands a substantial improvement, to mitigate significant losses of product during the purification of the target molecule..$^{[33]}$

Substantial opportunities exist within waste and low value streams of agriculture, horticulture and forestry. Examples include lipid-extracted algal residues that are generated during biodiesel production, side branches from plantation trees remaining unused in timber and paper manufacture, the non-edible portion of food crops, peels and skins from vegetables and fruits that derive from the food processing industry, and wastes from fermentation processes, such as in the manufacture of bioalcohol, or the use of algal residues (i.e. residual biomass from these processes). While there have been excellent discoveries towards the conversion of cellulosic materials (preferably native untreated cellulose or lignocellulosic feedstocks, including their fractionation in benign processes ${ }^{[178,179]}$ ) into platform chemicals, and while these efforts have led to deeper insights and provided glimpses of potential solutions, the problem remains unsolved. Many current practices rely on pre-treatment processes which add unwanted levels of complexity or energy consumption. If cellulose can be converted into valuable materials in a process that improves significantly upon the commercial Biofine, or OxFA process, then substantial scientific and, potentially, industrial progress will have been made. The optimum system will be able to operate directly on cellulose or lignocellulose, without requirements for its pre-treatment, under mild conditions, will produce high yields of desirable target molecules in selective transformations, and will employ robust catalysts. Preferably, the catalysts will be inexpensive and recoverable and reusable, and will contain the functionality required to perform the complexity of tasks necessary to convert cellulose into platform chemicals, namely, hydrolysis, isomerisation, dehydration, retro-aldol reactions and rehydration steps. This is a lofty goal for workers in this area, one to which real progress is being made by building on the foundations of deep understanding that is being achieved by fundamental studies. Despite the progress that has been made, there is much to be done before this problem has been solved.

Arguably, the most promising line of investigation at present includes the use of ionic liquids, which frequently perform as functional solvents that are instrumental in simplifying the role of added catalysts. Ionic solvents have undoubtedly become recognised as highly suitable media for the synthesis of valuable small molecule products from cellulose and, in some instances, lignocellulosic biomass. The wide variety of conventional imidazolium-based ILs and the availability of cheap alternatives, such as DESs and inorganic molten salt hydrates, provide substantial scope for deeper investigations.

\section{Acknowledgements}

We thank the University of Technology Sydney for financial support.

Keywords: carbohydrate chemistry $\bullet$ catalysis $\bullet$ green chemistry - platform chemicals 
[1] H. Yamamoto, in Inventing reactions. Topics in organometallic chemistry, Vol. 44 (Ed.: L. Gooßen), Springer, Berlin, Heidelberg, 2012; pp. 315334.

[2] T.H. Lowry, K.S. Richardson, Mechanism and theory in organic chemistry, Harper\&Row, New York, 1987.

[3] D.B.G. Williams, M. Lawton, J. Mol. Catal. A: Chem. 2010, 317, 68-71.

[4] P. Gupta, S. Paul, Catal. Today 2014, 236, 153-170.

[5] a) H. Yamamoto, K. Futatsugi, Angew. Chem. 2005, 117, 1958-1977; b) H. Yamamoto, K. Futatsugi, Angew. Chem. Int. Ed. 2005, 44, 1924-1942.

[6] H. Yamamoto, K. Futatsugi, in Acid Catalysis in Modern Organic Synthesis, Vol. 2 (Eds.: H. Yamamoto, K. Ishihara), Wiley- $\mathrm{VCH}$ Weinheim, 2008, pp. 1-34.

[7] D.B.G. Williams, T. Bredenkamp, ChemCatChem 2012, 4, 206-208.

[8] D.B.G. Williams, M.S. Sibiya, P.S. Van Heerden, Fuel Process. Technol. 2012, 94, 75-79.

[9] D.B.G. Williams, J.M. Mason, C.J Tristram, S.F.R. Hinkley, Macromolecules 2015, 48, 8497-8508.

[10] R.A. Sheldon, I. Arends, U. Hanefeld, Green chemistry and catalysis; Wiley-VCH GmbH \& Co. KGaA, Weinheim, 2007.

[11] J.W. Döbereiner, Annalen der Pharmacie 1832, 3, 141-146.

[12] Malaguti, Liebigs Annalen 1836, 14, 52-67.

[13] A. Corma Canos, S. Iborra, A. Velty, Chem. Rev. 2007, 107, 2411-2502.

[14] P.L. Dhepe, A. Fukuoka, ChemSusChem 2008, 1, 969-975.

[15] R. Rinaldi, F. Schüth, Energy Environ. Sci. 2009, 2, 610-626.

[16] R. Rinaldi, F. Schüth, ChemSusChem 2009, 2, 1096-1107.

[17] M. Hara, Energy Environ. Sci. 2010, 3, 601-607.

[18] M. Dusselier, M. Mascal, B.F. Sels, in Selective catalysis for renewable feedstocks and chemicals. Top. Cur. Chem., Vol 353 (Ed.: K. Nicholas), Springer, Cham, 2014, pp. 1-40.

[19] Y. Zhang, E.Y.-X. Chen, in Selective catalysis for renewable feedstocks and chemicals. Top. Cur. Chem., Vol 353 (Ed.: K. Nicholas), Springer Cham, 2014, pp. 185-227.

[20] J.J. Bozell, in Selective catalysis for renewable feedstocks and chemicals Top. Cur. Chem., Vol 353 (Ed.: K. Nicholas), Springer, Cham, 2014, pp. 229-255.

[21] A.F. Lee, J.A. Bennett, J.C. Manayil, K. Wilson, Chem. Soc. Rev. 2014, 43, 7887-7916.

[22] I. Delidovich, P.J.C. Hausoul, L. Deng, R. Pfützenreuter, M. Rose, R. Palkovits, Chem. Rev. 2016, 116, 1540-1599.

[23] a) D. Klemm, B. Heublein, H.-P. Fink, A. Bohn, Angew. Chem. 2005, 117, 3422-3458; b) D. Klemm, B. Heublein, H.-P. Fink, A. Bohn, Angew. Chem. Int. Ed. 2005, 44, 3358-3393.

[24] L. Negahdar, I. Delidovich, R. Palkovits, Appl. Catal., B 2016, 184, 285298.

[25] V. Choudhary, S.H. Mushrif, C. Ho, A. Anderko, V. Nikolakis, N.S. Marinkovic, A.I. Frenkel, S.I. Sandler, D.G. Vlachos, J. Am. Chem. Soc. 2013, 135, 3997-4006.

[26] M. Dusselier, B.F. Sels, in Selective catalysis for renewable feedstocks and chemicals. Top. Cur. Chem., Vol 353 (Ed.: K. Nicholas), Springer, Cham, 2014, pp. 85-125.

[27] X. Hu, C. Lievens, A. Larcher, C.Z. Li, Bioresour. Technol. 2011, 102 10104-10113

[28] I. Delidovich, K. Leonhard, R. Palkovits, Energy Environ. Sci. 2014, 7, 2803-2830.

[29] M. Dusselier, R. De Clercq, R. Cornelis, B.F. Sels, Catalysis Today 2017, 279, 339-344

[30] P.L. Dhepe, R. Sahu, Green Chem. 2010, 12, 2153-2156.

[31] J.J. Verendel, T.L. Church, P.G. Andersson, Synthesis 2011, 11, 16491677.

[32] M.J. Climent, A. Corma, S. Iborra, Green Chem. 2011, 13, 520-540.

[33] R.J. Van Putten, J.C. Van Der Waal, E. De Jong, C.B. Rasrendra, H.J. Heeres, J.G. De Vries, Chem. Rev. 2013, 113, 1499-1597.

[34] S.P. Teong, G. Yi, Y. Zhang, Green Chem. 2014, 16, 2015-2026.

[35] W. Deng, Q. Zhang, Y. Wang, Sci. China Chem. 2015, 58, 29-46.
[36] R. Breslow, in Green Solvents. Handbook of Green Chemistry. Vol. 5 (Ed.: P. Anastas), Wiley-VCH Verlag GmbH \& Co. KGaA, Weinheim, 2010, pp. 1-29.

[37] M. Balat, H. Balat, Appl. Energy 2009, 86, 2273-2282.

[38] T. Ghaffar, M. Irshad, Z. Anwar, T. Aqil, Z. Zulifqar, A. Tariq, M. Kamran, N. Ehsan, S. Mehmood, Journal of Radiation Research and Applied Sciences 2014, 7, 222-229,

[39] Q. Yang, X. Pan, Bioenergy Res. 2016, 9, 578-586.

[40] T. Li, S. Shen, B. Cai, Y. Wang, X. Peng, Y. Li, RSC Adv. 2016, 6, 9192191929.

[41] Z. Jiang, J. Yi, J. Li, T. He, C. Hu, ChemSusChem 2015, 8, 1901-1907.

[42] A. Shrotri, H. Kobayashi, A. Fukuoka, ChemCatChem 2016, 8, 1059 1064

[43] H.H. Yoon, Biotechnol.Bioprocess Eng. 1997, 2, 101-104

[44] Z. Kádár, Z. Szengyel, K. Réczey, Ind. Crops Prod. 2004, 20, 103-110.

[45] S. Brethauer, C.E. Wyman, Bioresour. Technol. 2010, 101, 4862-4874.

[46] R.W. Nagorski, J.P. Richard, J. Am. Chem. Soc. 2001, 123, 794-802.

[47] R. Bermejo-Deval, R.S. Assary, E. Nikolla, M. Moliner, Y. RománLeshkov, Proc. Nat. Acad. Sci. U.S.A. 2012, 109, 9727-9732.

[48] V. Choudhary, A.B. Pinar, R.F. Lobo, D.G. Vlachos, S.I. Sandler, ChemsusChem 2013, 6, 2369-2376.

[49] S.H. Mushrif, J.J. Varghese, D.G. Vlachos, Phys. Chem. Chem. Phys. 2014, 16, 19564-19572.

[50] J. Tang, X. Guo, L. Zhu, C. Hu, ACS Catal. 2015, 5, 5097-5103.

[51] J.P. Richard, J. Am. Chem. Soc. 1984, 106, 4926-4936.

[52] M. Moliner, Y. Román-Leshkov, M.E. Davis, Proc. Nat. Acad. Sci. U.S.A 2010, 107, 6164-6168.

[53] S. Saravanamurugan, A. Riisager, E. Taarning, S. Meier Chem CatChem 2016, 8, 3107-3111.

[54] S. Saravanamurugan, M. Paniagua, J.A. Melero, A. Riisager, J. Amer Chem. Soc. 2013, 135, 5246-5249.

[55] S. Zhao, X. Guo, P. Bai, L. Lv, Asian J. Chem. 2014, 26, 4537-4543.

[56] A.S. Nagpure, A.K. Venugopal, N. Lucas, M. Manikandan, R Thirumalaiswamy, S. Chilukuri, Catal. Sci. Technol. 2015, 5, 1463-1472.

[57] B. Liu, Z. Zhang, ChemSusChem 2016, 9, 2015-2036.

[58] R.S. Assary, P.C. Redfern, J.R. Hammond, J. Greeley, L.A. Curtiss J.Phys. Chem. B 2010, 114, 9002-9009.

[59] B. Xiang, Y. Wang, T. Qi, H.-Q. Yang, C.-W. Hu, J. Catal. 2017, 352 586-598.

[60] L.-K. Ren, L.-F. Zhu, T. Qi, J.-Q. Tang, H.-Q. Yang, C.-W. Hu, ACS Catal. 2017, 7, $2199-2212$.

[61] M.J. Antal, W.S. Mok, G.N. Richards, Carbohydr. Res. 1990, 199, $91-$ 109.

[62] C. Moreau, R. Durand, S. Razigade, J. Duhamet, P. Faugeras, P.Rivalier, P. Ros, G. Avignon, Appl. Catal., A 1996, 145, 211-224.

[63] J.N. Chheda, Y. Román-Leshkov, J.A. Dumesic, Green Chem. 2007, 9, 342-350.

[64] Y. Román-Leshkov, C.J. Barrett, Z.Y. Liu, J.A. Dumesic, Nature 2007, 447, 982-985.

[65] P. Wrigstedt, J. Keskiväli, M. Leskelä, T. Repo, ChemCatChem 2015, 7, 501-507.

[66] J. Tang, L. Zhu, X. Fu, J. Dai, X. Guo, C. Hu, ACS Catal. 2017, 7, 256266.

[67] L. Zhu, J. Dai, M. Liu, D. Tang, S. Liu, C. Hu, ChemSusChem 2016, 9 2174-2181.

[68] J. Dai, L. Zhu, D. Tang, X. Fu, J. Tang, X. Guo, C. Hu, Green Chem 2017, 19, 1932-1939.

[69] X. Guo, J. Tang, B. Xiang, L. Zhu, H. Yang, C. Hu, ChemCatChem 2017 9, 3218-3225.

[70] Y. Yang, C. Hu, M.M. Abu-Omar, J. Mol. Catal. A: Chem. 2013, 376, 98 102.

[71] Y. Román-Leshkov, J.A. Dumesic, Top. Catal. 2009, 52, 297-303.

[72] Y.J. Pagán-Torres, T. Wang, J.M.R. Gallo, B.H. Shanks, J.A. Dumesic, ACS Catal. 2012, 2, 930-934. 
[73] R.A. Bell, G.G. Christoph, F.R. Fronczek, R.E. Marsh, Science 1975, 190, 151-152.

[74] E.S. Stoyanov, I.V. Stoyanova, C.A. Reed, Chem. Sci. 2011, 2, 462-472.

[75] R.C. Weast, Handbook of Chemistry and Physics, 66th ed., CRC Press, Boca Raton, 1985

[76] I.K.M. Yu, D.C.W. Tsang, A.C.K. Yip, S.S. Chen, Y.S. Ok, C.S. Poon, Bioresour. Technol. 2016, 219, 338-347.

[77] Y. Yang, C. Hu, M.M. Abu-Omar, Bioresour. Technol. 2012, 116, 190 194.

[78] W. Deng, M. Liu, Q. Zhang, Y. Wang, Catal. Today 2011, 164, 461-466.

[79] Y. Yang, C. Hu, M.M. Abu-Omar, ChemSusChem 2012, 5, 405-410.

[80] Y. Yang, C. Hu, M.M. Abu-Omar, Green Chem. 2012, 14, 509-513.

[81] Y. Luo, Z. Li, Y. Zuo, Z. Su, C. Hu, ACS Sustain. Chem.Eng. 2017, 5, 8137-8147.

[82] K.J. Zeitsch, The chemistry and technology of furfural and its many byproducts, Vol. 13,1st ed., Elsevier, Amsterdam, 2000.

[83] H. Xia, S. Xu, X. Yan, S. Zuo, Fuel Process. Technol. 2016, 152, 140 146.

[84] J. Li, Y. Ma, L. Wang, Z. Song, H. Li, T. Wang, H. Li, Catalysts 2015, 6, $1-12$

[85] B. Cornils, W.A. Herrmann, C.-H. Wong, H.-W. Zanthoff, Catalysis from A to Z: A Concise Encyclopedia, 4 Volume Set, 4th ed., Wiley- $\mathrm{VCH}$ Weinheim, 2013

[86] K. Shimizu, R. Uozumi, A. Satsuma, Catal. Commun. 2009, 10, 18491853.

[87] A. Takagaki, M. Ohara, S. Nishimura, K. Ebitani, Chem. Commun. 2009 41, 6276-6278.

[88] X. Tong, Y. Ma, Y. Li, Appl. Catal., A 2010, 385, 1-13.

[89] V.A. Klushin, K.I. Galkin, V.P. Kashparova, E.A. Krivodaeva, O.A. Kravchenko, N.V. Smirnova, V.M. Chernyshev, V.P. Ananikov, Russ. J. Org. Chem. 2016, 52, 783-787.

[90] R.L. de Souza, H. Yu, F. Rataboul, N. Essayem, Challenges 2012, 3, 212-232.

[91] A. Jain, A.M. Shore, S.C. Jonnalagadda, K.V. Ramanujachary, A. Mugweru, Appl. Catal., A 2015, 489, 72-76.

[92] L. Atanda, M. Konarova, Q. Ma, S. Mukundan, A. Shrotri, J. Beltramini, Catal. Sci. Tech. 2016, 6, 6257-6266.

[93] X. Fu, J. Dai, X. Guo, J. Tang, L. Zhu, C. Hu, Green Chem. 2017, 19 3334-3343.

[94] X. Zhang, P. Murria, Y. Jiang, W. Xiao, H.I. Kenttämaa, M.M. Abu-Omar, N.S. Mosier, Green Chem. 2016, 18, 5219-5229.

[95] P. Carniti, A. Gervasini, M. Marzo, Catal. Commun. 2011, 12, 1122-1126.

[96] M. Marzo, A. Gervasini, P. Carniti, Catal. Today 2012, 192, 89-95.

[97] H.T. Kreissl, K. Nakagawa, Y.K. Peng, Y. Koito, J. Zheng, S.C.E. Tsang, J. Catal. 2016, 338, 329-339.

[98] S. Zhao, M. Cheng, J. Li, J. Tian, X. Wang, Chem. Commun. 2011, 47, 2176-20178.

[99] a) M. Mascal, E.B. Nikitin, Angew. Chem. 2008, 120, 8042-8044; b) M. Mascal, E.B. Nikitin, Angew. Chem. Int. Ed. 2008, 47, 7924-7926.

[100] M. Mascal, E.B. Nikitin, ChemSusChem 2009, 2, 423-426.

[101] M. Mascal, E.B. Nikitin, Green Chem. 2010, 12, 370-373.

[102] M. Mascal (Regents of the University of California), U.S. 7829732, 2010

[103] Y. Yang, M.M. Abu-Omar, C. Hu, Appl. Energy 2012, 99, 80-84.

[104] C.M. Lew, N. Rajabbeigi, M. Tsapatsis, Ind. Eng. Chem. Res. 2012, 51, 5364-5366.

[105] H. Li, K.S. Govind, R. Kotni, S. Shunmugavel, A. Riisager, S. Yang, Energy Convers. Manage. 2014, 88, 1245-1251.

[106] H. Xin, T. Zhang, W. Li, M. Su, S. Li, Q. Shao, L. Ma, RSC Adv. 2017, 7, 41546-41551.

[107] D.J. Hayes, S. Fitzpatrick, M.H.B. Hayes, J. Ross, in Biorefineries Industrial Processes and Products: Status Quo and Future Directions (Eds.: B. Kamm, P.R. Gruber, M. Kamm), Wiley-VCH Verlag GmbH \& Co. KGaA, Weinheim, 2006; pp. 139-164
[108] M. Mascal, S. Dutta, in Selective catalysis for renewable feedstocks and chemicals. Top. Cur. Chem., Vol 353 (Eds.: K. Nicholas), Springer, Cham, 2014, pp. 41-83.

[109] S.W. Fitzpatrick (Biofine Inc.), U.S. 5608105, 1997.

[110] S.W. Fitzpatrick (Biofine Technology, LLC), U.S. 9481626, 2016.

[111] R. Weingarten, W.C. Conner, G.W. Huber, Energy Environ. Sci. 2012, 5 7559-7574.

[112] J. Potvin, E. Sorlien, J. Hegner, B. DeBoef, B.L. Lucht, Tetrahedron Lett 2011, 52, 5891-5893.

[113] H. Yang, L. Wang, L. Jia, C. Qiu, Q. Pang, X. Pan, Ind. Eng. Chem. Res. 2014, 53, 6562-6568.

[114] L. Peng, L. Lin, J. Zhang, J. Zhuang, B .Zhang, Y. Gong, Molecules 2010 $15,5258-5272$

[115] Y. Luo, L. Hu, D. Tong, C. Hu, RSC Adv. 2014, 4, 24194-24206.

[116] Y. Luo, J. Fan, V.L. Budarin, C. Hu, J.H. Clark, Green Chem. 2017, 19 4889-4899.

[117] S. Van de Vyver, J. Thomas, J. Geboers, S. Keyzer, M. Smet, W.Dehaen, P. Jacobs, B.F. Sels, Energy Environ. Sci. 2011, 4, 3601-3610.

[118] F. Yu, J. Thomas, S. Van de Vyver, M. Smet, W. Dehaen, B.F. Sels, Green Chem. 2016, 18, 1694-1705.

[119] W. Liu, Y. Hou, W. Wu, Z. Liu, Q. Liu, S. Tian, K.N. Marsh, Ind. Eng Chem. Res. 2012, 51, 15503-15508.

[120] A. Démolis, N. Essayem, F. Rataboul, ACS Sustain. Chem.Eng. 2014, 2 1338-1352.

[121] K. Tominaga, A. Mori, Y. Fukushima, S. Shimada, K. Sato, Green Chem. 2011, 13, 810-812.

[122] D. Bianchi, A.M. Romano (Polimeri Europa S.p.A.), E.P. 2300410, 2011 [123] A.M. Khenkin, R. Neumann, J. Am. Chem. Soc. 2008, 130, 14474-14476.

[124] R. Wölfel, N. Taccardi, A. Bösmann, P. Wasserscheid, Green Chemistry 2011, 13, 2759-2763.

[125] J. Albert, R. Wölfel, A. Bösmann, P. Wasserscheid, Energy Environ. Sci. 2012, 5, 7956

[126] C. Johansson, in Handbook of Thermoplastics, Second Edition (Eds. O. Olabisi, K. Adewale), CRC Press, Boca Raton, 2016; pp. 835-876.

[127] M. Dusselier, P. VanWouwe, F. de Clippel, J. Dijkmans, D.W. Gammon, B.F. Sels, ChemCatChem 2013, 5, 569-575.

[128] J. Zhang, X. Liu, M. Sun, X. Ma, Y. Han, ACS Catal. 2012, 8, 1698-1702.

[129] C.B. Rasrendra, I.G.B.N. Makertihartha, S. Adisasmito, H.J. Heeres, Top. Catal. 2010, 53, 1241-1247.

[130] Y. Wang, W. Deng, B. Wang, Q. Zhang, X. Wan, Z. Tang, Y. Wang, C. Zhu, Z. Cao, G. Wang, H. Wan, Nat. Commun. 2013, 4, 2141.

[131] F.-F. Wang, C.-L. Liu, W.-S. Dong, Green Chem. 2013, 15, 2091-2095.

[132] R. De Clercq, M. Dusselier, J. Dijkmans, R.I. lacobescu, Y. Pontikes, B.F. Sels, ACS Catal. 2015, 5, 5803-5811.

[133] A. Sølvhøj, E. Taarning, R. Madsen, M. Brookhart, J.M. Garner, P.J. Fagan, J.C. Calabrese, B. Sels, T. Skrydstrup, E. Taarning, Green Chem. 2016, 18, 5448-5455.

[134] H.-S. Chen, A. Wang, H. Sorek, J.D. Lewis, Y. Román-Leshkov, A.T. Bell, ChemistrySelect 2016, 1, 4167-4172

[135] K. Dong, X. Liu, H. Dong, X. Zhang, S. Zhang, Chem. Rev. 2017, 117 6636-6695.

[136] A. Kuchenbuchand, R. Giernoth, ChemistryOpen 2015, 4, 677-681.

[137] R.L. Vekariya, J. Mol. Liq. 2017, 227, 44-60.

[138] Z. Zhang, J. Song, B. Han, Chem. Rev. 2017, 117, 6834-6880.

[139] H. Guo, X. Qi, L. Li, R.L. Smith, Bioresour. Technol. 2012, 116, 355-359.

[140] S. Kassaye, K.K. Pant, S. Jain, Fuel Process. Technol. 2016, 148, 289 294.

[141] Arifin, M. Puripat, D. Yokogawa, V. Parasuk, S. Irle, J. Comput. Chem. 2016, 37, 327-335.

[142] H. Zhao, J.E. Holladay, H. Brown, Z.C. Zhang, Science 2007, 316, 15971600

[143] C. Li, Z. Zhang, Z.K. Zhao, Tetrahedron Lett. 2009, 50, 5403-5405.

[144] M. Nüchter, B. Ondruschka, W. Bonrath, A. Gum, Green Chem. 2004, 6, 128-141. 
[145] a) C.O. Kappe, Angew. Chem. 2004, 116, 6408-6443; b) C.O. Kappe, Angew. Chem. Int. Ed. 2004, 43, 6250-6284.

[146] Z. Zhang, Z.K. Zhao, Bioresour. Technol. 2010, 101, 1111-1114.

[147] C. Van Nguyen, D. Lewis, W.H. Chen, H.W. Huang, Z.A. ALOthman, Y. Yamauchi, K.C.W. Wu, Catal. Today 2016, 278, 344-349.

[148] Y. Su, H.M. Brown, X. Huang, X.D. Zhou, J.E. Amonette, Z.C. Zhang, Appl. Catal., A 2009, 361, 117-122.

[149] Y. Su, H.M. Brown, G. Li, X.D. Zhou, J.E. Amonette, J.L. Fulton, D.M. Camaioni, Z.C. Zhang, Appl. Catal., A 2011, 391, 436-442.

[150] H. Abou-Yousef, E.B. Hassan, P. Steele, J. Fuel Chem. Technol. 2013 41, 214-222.

[151] L. Hu, G. Zhao, X. Tang, Z. Wu, J. Xu, L. Lin, S. Liu, Bioresour. Technol. 2013, 148, 501-507.

[152] A.S. Amarasekara, Chem. Rev. 2016, 116, 6133-6183.

[153] Z.D. Ding, J.C. Shi, J.J. Xiao, W.X. Gu, C.G. Zheng, H.J. Wang, Carbohydr. Polym. 2012, 90, 792-798.

[154] H. Li, Q. Zhang, X. Liu, F. Chang, D. Hu, Y. Zhang, W. Xue, S. Yang, RSC Adv. 2013, 3, 3648-3654.

[155] S. Siankevich, Z. Fei, R. Scopelliti, P.G. Jessop, J. Zhang, N. Yan, P.J. Dyson, ChemSusChem 2016, 9, 2089-2096.

[156] H. Ren, Y. Zhou, L. Liu, Bioresour. Technol. 2013, 129, 616-619.

[157] J.B. Binder, R.T. Raines, J. Am. Chem. Soc. 2009, 131, 1979-1985.

[158] I.A. Masiutin, A.A. Novikov, A.A. Litvin, D.S. Kopitsyn, D.A. Beskorovaynaya, E.V. Ivanov, Starch-Staerke 2015, 68, 637-643.

[159] S. Xiao, B. Liu, Y. Wang, Z. Fang, Z. Zhang, Bioresour. Technol. 2014, $151,361-366$

[160] S. Wang, Y. Du, W. Zhang, X. Cheng, J. Wang, Korean J. Chem. Eng. 2014, 31, 1786-1791.

[161] E.L. Smith, A.P. Abbott, K.S. Ryder, Chem. Rev. 2014, 114, 1106011082.

[162] M. Hayyan, Y.P. Mbous, C.Y. Looi, W.F. Wong, A. Hayyan, Z. Salleh, O Mohd-Ali, SpringerPlus 2016, 5, 913.
[163] S. Hu, Z. Zhang, Y. Zhou, J. Song, H. Fan, B. Han, Green Chem. 2009, 11, 873-877.

[164] L. Zhang, H. Yu, BioResources 2013, 8, 6014-6025.

[165] F. Ilgen, D. Ott, D. Kralisch, C. Reil, A. Palmberger, B. Konig, Green Chem. 2009, 11, 1948-1954.

[166] N.A.M. Nor, W.A.W. Mustapha, O. Hassan, Procedia Chem. 2016, 18 147-154.

[167] Q. Zhang, M. Benoit, K. De Oliveira Vigier, J. Barrault, F. Jérôme, Chem Eur. J. 2012, 18, 1043-1046.

[168] K.D.O. Vigier, G. Chatel, F. Jérôme, ChemCatChem 2015, 7, 1250-1260

[169] J.A. Sirviö, M. Visanko, H. Liimatainen, Biomacromolecules 2016, 17, 3025-3032.

[170] S. Sen, J.D. Martin, D.S. Argyropoulos, ACS Sustainable Chem. Eng. 2013, 1, 858-870.

[171] S. Fischer, H. Leipner, E. Brendler, W. Voigt, K. Fischer, in Polysaccharide Applications. Vol. 737 (Eds.: M.A. El-Nokaly, H.A. Soini), American Chemical Society, Washington, 1999, pp. 143-150.

[172] S. Fischer, H. Leipner, K. Thümmler, E. Brendler, J. Peters, Cellulose 2003, 10, 227-236.

[173] L. Yang, G. Li, F. Yang, S.M. Zhang, H.X. Fan, X.N. Lv, Carbohydr. Res. 2011, 346, 2304-2307.

[174] T. Deng, X. Cui, Y. Qi, Y. Wang, X. Hou, Y. Zhu, Chem. Commun. 2012 48, 5494-5496.

[175] Y.-R. Zhang, N. Li, M.-F. Li, Y.-M. Fan, RSC Adv. 2016, 6, 21347-21351.

[176] R.J. Wilcox, B.P. Losey, J.C.W. Folmer, J.D. Martin, M. Zeller, R. Sommer, Inorg. Chem. 2015, 54, 1109-1119.

[177] S. Sen, B.P. Losey, E.E. Gordon, D.S. Argyropoulos, J.D. Martin, J.Phys. Chem. B 2016, 120, 1134-1141.

[178] T. Renders, S. van den Bosch, S.-F. Koelewijn, W. Schutyser, B.F. Sels, Energy Environ. Sci. 2017, 10, 1551-1557.

[179] Y. Luo, J. Fan, V.L. Budarin, C. Hu, J.H. Clark, Green Chem. 2017, 19, 4889-4899. 
Entry for the Table of Contents (Please choose one layout)

Layout 1:

\section{REVIEW}

This review covers advances in the acid-catalysed conversion of low value (poly)saccharides into value added organic building block chemicals (platform molecules), with a focus on those transformations performed in aqueous or alternative solvents. It articulates the overall role of acid catalyst and solvent employed to the valorisation of carbohydrates to create a concept of sustainable processes.

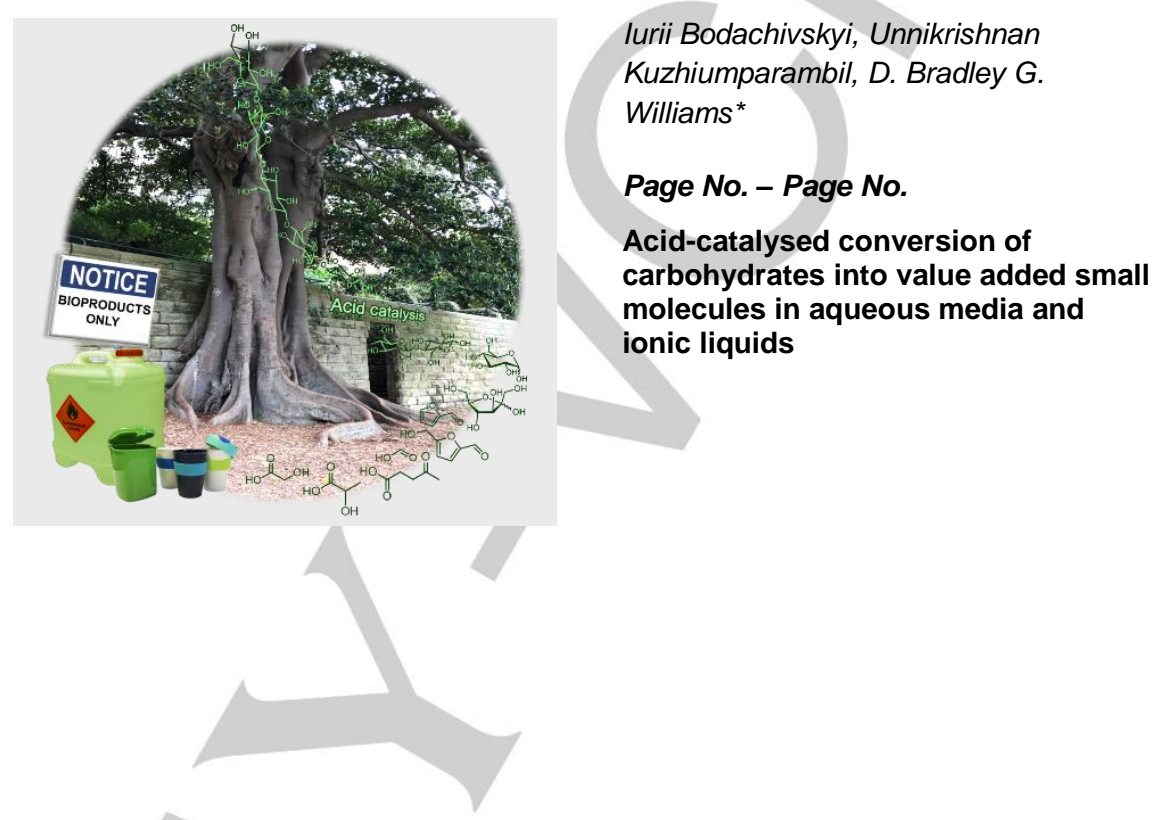

